\title{
Web Engineering at the Frontier of the Web 2.0: Design Patterns for Online 3D Shared Spaces
}

\author{
Nicoletta Di Blas • Franca Garzotto • Caterina Poggi
}

Received: 19 December 2008 / Revised: 6 April 2009

Accepted: 25 June 2009 / Published online: 11 July 2009

(C) Springer Science + Business Media, LLC 2009

\begin{abstract}
Online 3D Shared Spaces (3DSSs) can be regarded as a frontier of the Web 2.0, where users as participants contribute to create a meaningful, engaging experience. Like other complex web applications, the development and evolution of high-quality 3DSS applications requires methodological support - through models, methods, and principles. Yet, the application of structured, engineered approaches to this domain is largely unexplored. The purpose of this paper is to contribute to bridging Web Engineering to the 3DSS world by means of design patterns. We present five patterns that focus on two factors deemed necessary for effective experiences in a 3DSS: Presence (i.e. the feeling of "being there", typical of "virtual worlds") and Long-Term Engagement (typical of successful Web 2.0 communities). The patterns presented in the paper distil our largescale experiences with 3DSSs (that have involved so far over 9,000 youngsters from 3 continents) and are discussed in the light of existing literature.
\end{abstract}

Keywords Web 2.0 - multiuser 3D shared space - virtual world · web engineering · design · design pattern $\cdot$ user experience $\cdot$ presence $\cdot$ engagement $\cdot$ enjoyment

\section{Introduction}

The web arena is assisting today to an increased popularity [27], especially among youngsters, of online 3D Shared Spaces (3DSSs) such as those created in Second Life (SL),

\footnotetext{
N. Di Blas $\cdot$ F. Garzotto $(\bowtie)$

HOC Lab-Department of Electronics and Information, Politecnico di Milano, Milano, Italy e-mail: garzotto@elet.polimi.it

N. Di Blas

e-mail: diblas@elet.polimi.it

C. Poggi

Department of Curriculum and Instruction, College of Education, University of Wisconsin,

Madison, USA

e-mail: cpoggi@wisc.edu
} 
where thousands of young people today meet, talk, play, discuss, compete, learn. Can this phenomenon be regarded as a frontier aspect of the Web 2.0?

Indeed, 3DSSs move to the extreme consequence some key principles of the Web 2.0, as O'Reilly and Battelle pointed out in the opening talk of the first Web 2.0 conference [11]: "the end user is not only the user of the application but the participant, an integral part of the 'data' of the application, allowing the application to leverage the users who are using it"; web sites "have an 'Architecture of Participation' that encourages users to add value to the application as they use it",

In more conventional Web 2.0 applications such as wikis, blogs, social-networking sites, video sharing sites, or folksonomies, these concepts are implemented with data as the driving force. In 3DSSs, Web 2.0 buzzwords such as "social web", "collaboration", "sharing of user's something", are reified more in terms of "presence" and "experience" than in terms of "content". If it is true that a system like Second Life hosts a large amount of user-generated content, ranging from avatar personalization ${ }^{1}$ such as custom hair and clothing, to scripted objects in the 3D space such as furniture, buildings, flora or fauna, a space created in this or in other platforms lives and grows only if multiple users "feel" there at the same time, move and do things together, perceive the others, and feel synchronously engaged and all this happens not just episodically, but repetitively-for weeks, months, or years.

The 3DSS phenomenon has been analyzed in the context of diverse disciplines and from different points of view, focusing on technology [12], graphic design, or implications of the use of these systems from a social [17, 18, 34, 49], educational [7, 8, 15], psychological [93] or cognitive perspective [18]. Many guidelines, heuristics, "claims" exist for 3DSS design, which are founded on practice or on theories from psychology and cognitive science. Still, they are spread in a vast number of publications produced by different communities (e.g., Human Computer Interaction, Computer Supported Collaborative Work, Computer Graphics, e-learning) and compose an unstructured, a-systematic, and fragmented body of knowledge where different design concerns (cognitive, social, visual, technological) are oftentimes intermixed, making it difficult for designers to retrieve, share, and reuse such valuable design know-how.

While it is clear that the construction and evolution of high-quality 3DSS applications for the World Wide Web requires methodological support such as is available for other kinds of complex web applications - through models, methods and principles [21, 62, 73] - the application of structured, engineered approaches to this application domain is largely unexplored: 3DSSs have seldom been investigated from the perspective of Web Engineering (WE), the discipline that concerns "the application of systematic, disciplined and quantifiable approaches to the cost-effective development and evolution of high-quality solutions in the World Wide Web" [90].

The purpose of this paper is to contribute to bridging WE to the 3DSS world by means of design patterns. A design pattern “... describes a problem which occurs over and over again in our environment and then describes the core of the solution to that problem, in such a way that you can use this solution a million times over, without ever doing it the same way twice" [3]. It provides a descriptive structure for integrating the analysis and the solution of a recurring problem, in a way that is sensitive to context, is informed by theory and evidence and is re-usable with a minimum degree of customization.

Our work provides a novel contribution in the arena of online 3DSSs where the concept of pattern is largely ignored and paves the ground towards a challenging research area for

\footnotetext{
${ }^{1}$ It is estimated that over 5 million different avatars were created by users from the launch of SL in 2003 to 2007 [79]
} 
the WE community. The patterns reported in this paper are a subset of a wider pattern language we have developed in the last five years. It represents an attempt of making more re-usable the design know-how spread in the current literature, or accumulated by the authors and their research group since 2001 in designing, developing and evaluating collaborative "experiences" in 3DSSs for youngsters in the context of a wide number of national and international projects. A very preliminary version of the patterns described here was defined in the context of the EC project TELL "Towards Effective network supported coLLaborative learning activities" [47]. A second formulation was evaluated by and discussed with a team of expert pattern writers in the context of EUROPLOP 2008the European Conference on Pattern Languages of Programs. Reported here is the new version, revised in depth after the comments and feedbacks received.

The paper is organized as follows: we first provide a short overview of the literature on design patterns, pinpointing how these engineering tools have been seldom exploited to support the design of 3DSSs. Then we discuss the design issues which our patterns focus on and frame these concepts in the context of the current state of the art. We continue by presenting five patterns structured according to Alexander's pattern schema [62]. We finally draw the conclusions, outlining the role of WE in the 3DSS arena and possible future directions in this domain.

\section{Where are patterns for online 3D shared spaces?}

Born in the architecture domain with the seminal works of C. Alexander, in the late eighties the idea of patterns took root in the distant soil of computer science, starting from software engineering, where patterns are generally acknowledged as a useful means to capture design experience and support reuse, which seems to be the keyword in achieving the economies of scale for developing affordable and usable applications in a more effective way $[20,23,38]$.

With the increasing interest of software design patterns in industry and academia, this concept has received an increasing attention of fields outside traditional software engineering, such as Hypermedia and Web Engineering [43, 72], Human-Computer Interaction (HCI) [14, 28, 77, 86], Computer Supported Cooperative Work (CSCW) [5, 76, 78] and e-learning [41, 42, 44].

This trend has also been witnessed by a proliferation of efforts in creating digital online catalogues of design patterns in specific domains. Here are some examples: the Hypermedia Design Patterns Repository [48]; the "design patterns for Web, GUI and Mobile Interfaces" by M. van Welie [85]; Erickson's Interaction Design Patterns web site, which also provides some domain specific patterns for game interfaces and social applications [36]; the ninety web design patterns by K. Van Duyne [84]; the thirty user interface patterns by J. Tidwell, featuring real-life examples from desktop applications to web sites and web applications for mobile devices [83]; the Pattern Language for CSCW in [58].

Many patterns generated by the communities of HCI, Computer-Supported Collaborative Work (CSCW) and e-learning are general enough to be helpful also for designers of 3DSSs, because they consider some characteristics of human-computer interaction, computer-mediated human-human communication, collaboration, or learning that hold in any technological environment. Still, such patterns provide limited support to the design of the interaction aspects that are peculiar of 3DSSs (as those discussed in the next sessions), nor are they shaped in such a way as to facilitate their application to the 3DSSs situation a designer is coping with. 
For example, the patterns on cooperation (e.g., "H3: Cooperative Experience" in [14] or "Collaboration in small groups" in [58]) address the general problem of how to support effective cooperation, but do not pinpoint the actual forces that may play in 3DSS environments and a designer may underestimate or simply not consider, nor do they use examples from experiences in these specific contexts. A notable exception is the pattern "Navigation" in [75]. It addresses the problem of how to design the movement capability of users in a shared (2D or 3D) space structured in different "rooms", so that they can perceive the space and the others, reporting one example in the 3DSS environment Active Worlds [1].

Finally, it is interesting to notice that in one of the first, and most quoted, publications on the Web 2.0 [67], the concept of pattern is strongly tied with the vision of the Web 2.0 (the subtitle being: "Design Patterns and Business Models for the Next Generation of Software"). But the patterns suggested in this paper are just drafted. Further works on patterns for the Web 2.0 either focus on technological issues (e.g., Ajax implementation [54]) or on socio/ethnographic/business aspects (e.g. "Web 2.0 Pattern Mining Workshop" [56]). Similarly, the announced book by Nickull et al. on Web 2.0 Patterns [65] will be mainly devoted (as claimed by authors) to software developers and business people.

As discussed in the next section, we look at 3DSS applications from a Web 2.0 perspectiveas "platforms for user's participation" - but, differently from existing patterns, we address the design of these systems mainly from the user interaction perspective.

\section{Our general approach to 3DSS design}

As in any technological context, the problem of designing high quality 3DSS applications can be addressed from multiple viewpoints and at different levels of abstraction. In this paper, we focus on some design characteristics that are peculiar of this class of systems and are related to the quality of the participatory "experience". In this regard, we take an "experience design" perspective, looking at this user-centered approach typical of HCI with the eyes of WE. The rest of this section discusses our design approach and frames it in the context of the current state of the art.

The term "experience" is associated to a wide range of concepts and no cohesive theory of experience and experience design currently exists. In HCI, an experience is broadly defined as the set of user-product interactions and all aspects of "experiencing" an interactive product - physical, sensual, emotional, social and aesthetic [2, 6, 57, 60, 66], while the concept of "quality of experience" expresses " how well a product serves its purposes, how well it fits into the entire context in which it is used, how pleasant, compelling and valuable it is for its users" [2].

Most of existing experience design approaches associate quality of experience to general attributes of the interface, such as usability and aesthetics [2, 6], for which a number of guidelines have been proposed. While these aspects are important for most interactive systems, including Web 2.0 applications, our patterns address design issues that characterize 3DSSs with respect to other classes of Web 2.0 environments or other kinds of interactive systems. In our opinion, the issue of creating 3DSS-based experiences requires a broader perspective in which two key concepts, virtual presence and long-term engagement, play a crucial role.

\subsection{Virtual presence}

A Web 2.0 application that uses conventional 2D layout is perceived as a "data \& function" centric interaction space shared with other users, where the interface is functional to content 
search and visualization and to the execution of the functions needed to create/update/tag/ share contents, and to communicate with other users, not necessarily synchronously. In 3D applications, the interaction space contains the interface to contents and functions, but is also a "place" per se, for experiencing the sense of self, of remote "others" who are synchronously there with you, and of the digital environment. This idea is captured by the concept of presence, in its multiple declinations [19, 35, 46, 53, 59, 74, 80, 81, 92, 94, 95].

Presence has been defined as "the subjective sensation of being in one place or environment, even when one is physically situated in another" [80]. In digital contexts, it refers to "experiencing the computer-generated environment rather than the actual physical locale." [46]

Heeter [46] divides the concept of presence for user experiences in technology mediated spaces into three dimensions, personal presence, social presence and environmental presence. Personal presence is a measure of the extent to which and the reasons why a person feel as if $\mathrm{s} / \mathrm{he}$ is in a virtual world (a concept sometimes also referred to as Physical Presence). Environmental presence refers to the extent to which the environment itself appears to know that you are there and reacts to you and is usually regarded as functional to achieve personal presence $[81,92,95]$. Social presence refers to the extent to which other beings (both living and synthetic) exist in the virtual world and appear to react to you. This concept is also referred to as Presence-in-absence, which highlights the distributed nature of the subjective sense of social others, that 'we' or 'they' are separated by time or space [35].

The exploration of the notion of presence and how to enforce it represents the largest body of research on the design of virtual experiences, because presence is at the heart of humans' desire to use media to move beyond the limit of body and sensory channels. HCI researchers and VR designers have tended to focus on personal (physical) presence [81, 92], trying to identify design features of virtual worlds that might contribute to convincing someone that $\mathrm{s} / \mathrm{he}$ is "there". Several works also exist addressing environmental and social presence [19, 35, 53, $59,74,94,95]$. It is interesting to observe that, even if most of existing researches on social presence focus on 3D (immersive or not) spaces, a number of works explore this concept also in the design of more conventional Web 2.0 applications, e.g., video or photo sharing [16, $24,52,68]$ and social-networking systems [25]; they investigate the benefits of the subjective sense of togetherness, of an unfolding social union with remote others on the quality for the experience and the design features that contribute to social presence.

Given the importance of enforcing presence in 3D experiences, the first set of patterns reported in this paper focus on the design issues related to this aspect. The second set of patterns addresses design for "long-term engagement", a concept discussed in the following section.

\subsection{Long-term engagement}

Long term engagement is defined as the degree of voluntary use of a system by different users in the long-term, spanning dozens, if not thousands, of interactions ${ }^{2}$ in a wide span of time [13]. Achieving long term engagement is an important concern for designers not only of 3D spaces but of Web 2.0 systems in general [51], being the participatory dimension in the long term a fundamental aspect: "the fact that (many) people are using or have used the application repeatedly, for significantly longer than few seconds or minutes and will keep using it after weeks or months or years, makes it more reliable for users, increases their

\footnotetext{
${ }^{2}$ This aspect is sometimes captured by the concept of "stickiness" for e-commerce web sites - a term that refers to getting people to stay on your site and getting them to return as regular visitors (making the application more appealing from a business perspective).
} 
satisfaction of being part of the community and ultimately contribute to the quality of the "experience in the large" [13, 37].

While most principles available in the experience design literature to date focus on engagement in the context of a single session or relatively short-term interactions, the problem of how to "design for long term engagement" has received only marginal attention in the HCI community. Recent studies pinpoint that enjoyment is fundamental to maintain engagement along the time [2,66]. Central to any human activity, enjoyment is a crucial driver to involve users emotionally and to create an intrinsically rewarding experience. Different sets of heuristic principles have been proposed in the HCI literature to promote enjoyment in interactive systems [55, 63], in particular e-games [82]. Most of these design guidelines operationalize the concepts of Csikszentmihalyi's Flow Theory [26]. According to this theory, a "flow state" is an optimal experience that is "... so intrinsically gratifying that people are willing to do it for its own sake, with little concern for what they will get out of it" and regardless of the fact that it is difficult or resource consuming.

Csikszentmihalyi's works is based on an extensive empirical research into what makes experiences enjoyable, involving interviews, questionnaires and other data collected over a dozen years from several thousand respondents. Csikszentmihalyi identifies a number of subjective feelings that are present in a flow state and are universal, irrespective of age, social class, culture, or gender: People experience a distorted sense of time, temporary losses of the perception of self-consciousness, a sense of discovery, a creative feeling of being transported into a new reality, a sense of personal control over the situation or activity, a deep but effortless involvement that removes awareness of the frustrations of everyday life. Csikszentmihalyi also proposes a number of characteristics for the activities in which people are involved that contribute to create flow and cause a sense of deep enjoyment so rewarding that people feel that expending a great deal of energy is worthwhile simply to be able to feel it. They should be goal-directed, bounded by rules and offer the user appropriate feedback on progress towards completing the tasks: if the person is sufficiently skilled and the tasks have clear goals and feedback, then s/he will feel a sense of control over the task. User's concentration is supported by activities that are intrinsically rewarding so that there is an effortlessness of action and require a high work-load balancing ability level and challenge so that all relevant skills are employed in it: in this way, tasks are enjoyable without being frustrating, focus of awareness is narrowed down to the activity itself and the person's attention is completely absorbed by it.

Social interaction is a further aspect that contributes to enjoyment, although it is not an element of flow (since it might interrupt concentration and immersion in the experience). As it is widely featured in the literature on user-experience, particularly on e-gaming design, social interaction is a powerful motivator for people to engage with a synchronous or asynchronous multiuser experience both in the short and in the long term. According to Dix [33], there are different types of social interaction, referred to as communicationcentered and activity-centered, which are oftentimes intermixed. Communication-centered social interaction focuses on contents and implications of exchanged messages, e.g., chatting and talking about themselves, discussing strategies and solutions with others. Activity-centered social interaction emphasizes user's activities related to the creation or modification of artefacts or the achievement of given goals, either doing things together with others, i.e., cooperating in situations that need more than one person to be involved and complementary skills and knowledge, or working against others, in situations of competition. All forms of social interactions promote enjoyment regardless of the fact that people like socialization forms supported by the system-people simply like the feeling of "being there with many", seeing other people's reactions and spending time with remote 
peers just watching others doing things. In addition, social interaction creates the feeling of being "a member of a group" (community), enhances the sense of social identity, enforce the feeling of self-recognition and it is a way "to make thinking visible" and to build a more tangible context for what is being done in the virtual world. Competition in particular adds emotions that make the experience more exciting and fun [87].

\section{Patterns for designing 3D shared spaces on the web}

The five patterns discussed in this paper address the early design phase of a 3DSS, which abstracts from any implementation concern and rather focuses on the definition of the user interaction features in the digital interaction environment that contribute to the quality of the experience in a 3DSS. In particular, our patterns' scope is the achievement of presence (in its multiple declinations), long term engagement and effective cooperation. Their main target audience are interaction designers who are responsible for conveying high level goals and needs set by the different stakeholders into the design characteristics of both the interactive digital medium (e.g., the visual properties of the 3D space, the graphics and behavior of the space and of the objects and agents, or "avatars", which populate it) - and the activities in which users are involved. Still, the development of a complex 3SDD application is a groupware process that call for the participation of all involved stakeholders; thus our design patterns represent also a means for communicating and sharing know-how among all members of a design team, including analysts, implementation developers and end users.

The patterns reported in this section build upon design principles and practices identified in the state of the art discussed in the previous sections, and distil the large experience we have gained so far running a number of 3D-based projects. We have developed collaborative 3D virtual environments since 2000, in the context of several projects. Their subject is heterogeneous, spanning from Leonardo da Vinci's machines (Virtual Leonardo Project [9]) to the Dead Sea Scrolls (Shrine Educational Experience Project [31]), from European Modern history (Learning@Europe Project, [30, 69]) to Italian Medieval History (Stori@Lombardia Project [70]) and the social value of sports (Learning@SocialSport Project, [32]), to fairy tales (FATE2 project $[39,40]$ ). All these projects are intended to provide engaging, enjoyable experiences, while also pursuing a number of educational goals; all have been researched, evaluated and refined over the years. Their implementation environment is WebTalk [10], a proprietary platform for 3D shared virtual worlds developed at our lab before the advent of Second Life (www.secondlife.com); recently, some projects have been extended their experiences with activities that users perform in Second Life worlds.

\subsection{Pattern format}

The formulation of our patterns follows the conceptual structure proposed by Alexander [3] and highlighted in Figure 1:

- Name: The pattern name is a meaningful and memorable identifier that succinctly grasps the essence of a problem in such a way as to be clearly understood by all members of a design community and a sudden association with the core feature of the referred design solution can be easily made.

- Context: From a clear definition of the environment in which the problem and the solution are likely to recur, a designer can understand the preconditions under which $\mathrm{s} / \mathrm{he}$ will probably meet the problem, thus improving the problem-matching process. 


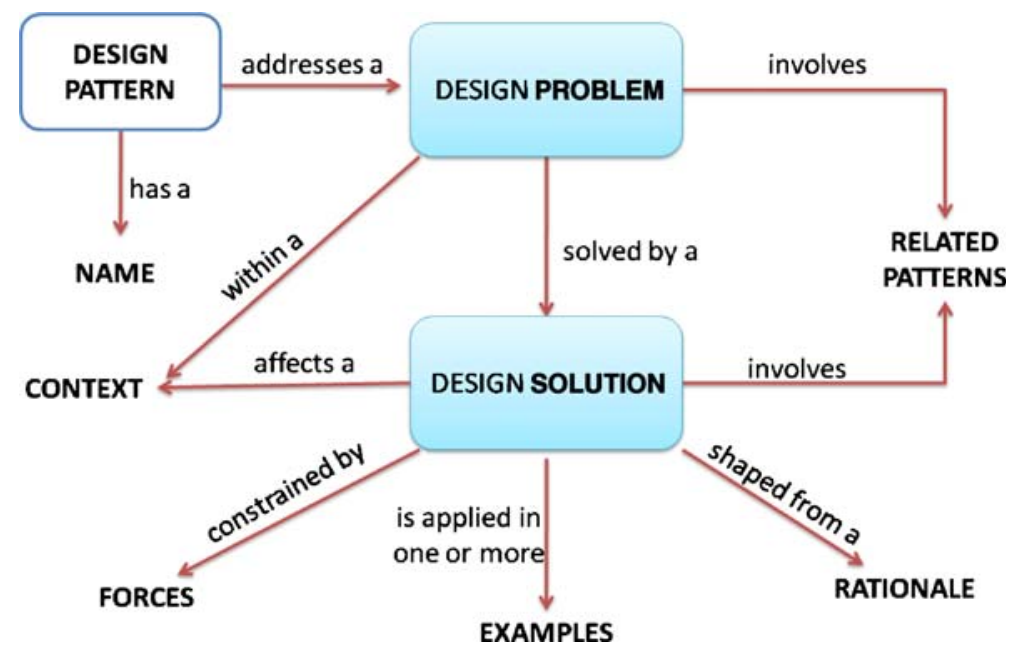

Figure 1 The conceptual structure of Alexander's design pattern.

- Problem: By knowing the problem, the designer should be able to evaluate the relevance and the applicability of that pattern to the situation $\mathrm{s} / \mathrm{he}$ is coping with and to achieve a better understanding of the potential effectiveness of the pattern.

- Forces: Forces define the constraints, relationships, contrast and conflicts permeating the scene in which the pattern acts. Explaining forces may help to realize which tradeoff must be considered while adapting the pattern to a specific design situation.

- Solution: The solution is the essence of the design experience the pattern wants to convey. A solution is composed of a list of rules or easy-to-remember guidelines describing how to shape the desired artifact, to help the designer while implementing the pattern in a concrete analogue situation.

- Rationale: The rationale should explain the key factors that make the pattern solution really useful, effective and valuable. The rationale tells us why the patterns provides a "good" solution to the stated design problem. The actual basic strategies by which forces and constraints are managed in order to achieve a certain task are also described here. While the pattern solution can be viewed as the body of the pattern which operates, the rationale is the soul of the pattern, its inner motivation of behaving.

- Examples: To help the designer understand a pattern's use and applicability, it could be especially illuminating to provide one or more sample examples and known uses of the pattern in specific contexts. To provide a pragmatic evidence to the proposed solution, the "Examples" component of our patterns will concretely render the solution by means of textual and visual examples from projects developed at our lab, or from relevant projects involving 3DSSs.

- Related Patterns: Relationships among patterns can be established for different reasons. A pattern can accomplish a specific task within a larger design strategy and its synergy with other patterns can more effectively achieve the goal of supporting design. Two or more patterns can be related because they try to solve a (portion of a) similar design problem, or because they can be considered as slightly different variants of the same design solution. Different patterns applicable in different contexts can share key factors or design elements, which is another reason why a relationship may arise. 


\subsection{Our patterns at a glance}

Before describing each pattern in detail, we provide a short description of their scope. The sequence of patterns follows the flow of our discussion in section 3, which introduces the concepts of Personal Presence, Environmental Presence, Social Presence, Long-Term Engagement, and Social Interaction. Some design issues related to each of these major topics are addressed by at least one pattern ${ }^{3}$.

\subsubsection{Pattern 1: "Where am I?"}

This pattern deals with the issue of Personal Presence (the feeling of being in the virtual space while you are located in a different physical place) and proposes how it can be enhanced by means of the visual graphic properties of the $3 \mathrm{D}$ space

\subsubsection{Pattern 2: "Does the space feel me?"}

This pattern deals with the issue of Environmental Presence (the fact that the virtual environment knows that users are there and manifests this awareness) and highlights how it can be enforced by means of (non necessarily realistic) feedbacks in response to the user's movements and actions

\subsubsection{Pattern 3: "What are our super-powers?"}

Users are represented in the 3D space as "avatars", i.e., user-controlled, not necessarily anthropomorphic characters. What avatars are/are not allowed to do in the virtual environment affects Environmental Presence and above all, Social Presence-how users know/guess/perceive their fellows and what they are doing, which is fundamental prerequisite for engaging in social interaction and, in particular, in cooperation. This pattern investigates this issue.

\subsubsection{Pattern 4: "What are we supposed to do?"}

Having multiple users cognitively immersed a virtual environment and mutually perceiving each other does not necessarily imply that they will engage in meaningful (individual or social) activities, repeatedly and along a significant period of time. This pattern explores how a carefully design of activities can foster long term engagement in 3DSSs.

\subsubsection{Pattern 5: "Shall we do it together?"}

Having multiple users logged in at the same time in a virtual environment and perceiving their mutual presence does not necessarily imply that they will get involved in social interaction and cooperate. This pattern identifies some solutions to design activities that can foster a team spirit and promote cooperation among all users participating in a 3DSS experiences.

\footnotetext{
$\overline{3}$ This is not to say that our pattern language is complete w.r.t. all possible problems and solutions related to the above design issues. As mentioned in section "Discussion and Conclusions", evaluating patterns from the perspective of "coverage" and "completeness" w.r.t. the design space of a given domain is a very complex problem, and represents an open issue of any pattern language.
} 


\subsection{Our patterns}

\subsubsection{Pattern 1: "Where am I?"}

Context Users logged in your 3DSS start experiencing the virtual space (not necessarily with others participating in the experience) while sitting at their own desk in front of a $2 \mathrm{D}$ screen.

Problem How should a 3D world be designed in terms of realism, spaces, dimensions, spatial depth, textures, so that personal presence can be experienced, i.e., users feel as if they were in the virtual environment rather than in their actual physical environment?

Forces Despite their name, 3D virtual environments are actually two-dimensional, just like the computer screen that shows them. Realistic virtual reproductions of real or imaginary locations make it easier for users to understand where they (indeed, their "avatars" - virtual alter egos in the digital space) are and, through suspension of disbelief, to imagine of being there themselves. Yet, high-fidelity graphics:

- $\quad$ is expensive to achieve;

- $\quad$ often imposes high technical requirements to the final user;

- does not necessarily convey the "magic" of being in the reproduced place;

- does not necessarily produce engagement.

\section{Solution}

- Use allusion rather than realism: reproducing a place in every single detail is difficult and very expensive, while a few familiar objects, textures, or simple buildings are usually enough for users to understand where their avatar is, to recognize existing landmarks, or to feel the particular "atmosphere" connected to that specific location;

- $\quad$ use geometric shapes, converging lines and striped tiles to convey the impression of distance, size and relative position;

- use image textures, lights, shadows and objects to create the illusion of spaces without actually building 3D virtual geometries;

- $\quad$ if the implementation platform allows it, limit the avatars' movements so that they can only look at certain areas of the environment from specific points of view, without really having access to them;

- $\quad$ keep users engaged by means of properly designed activities.

Rationale For years interactive 3D has been considered a challenging way to make the user experience more engaging in web sites designed for cultural or educational purposes (museums, archeological sites, natural sites, scientific labs, etc.). As a consequence, graphic designers and implementers have been pushed to invest enormous efforts to make interactive 3D environments as aesthetically pleasant, detailed and realistic as possible, attempting to reproduce the physical features and behaviors of the "real" world. Several interesting 3D virtual realities have been created with the above assumptions, e.g., in Second Life. Still, user experiences with these environments have often turned out to be not as satisfactory as expected. Many wonderful and highly realistic Second Life islands are 
deserts most of the time; usage data collected in a number of 3D online applications highlights that the interest for mere 3D interaction vanes down after a short time, no matter how carefully reconstructed the digital world is [71].

If what we want to achieve in our 3DSSs is that users forget about the chair they are sitting on and the computer screen they are looking at, then the realistic, highly detailed characteristics of the 3D environment are apparently less significant than the possibility of interacting with the environment, meeting other people, communicating with them, sharing resources and getting together to achieve a common goal. In other words, the key success factor is the feeling of "being there", the so called personal presence $[46,80]$ and, in multiusers situations, "of being there with others" that can be reached by means of meaningful, properly designed activities (either individual or collective - see patterns 4 and 5). In our experience, creating a replica of a real space (e.g. a city, a building, a monument, a public space) is not only hard (and expensive) to achieve, but is largely irrelevant for engaging users in a "large" (i.e., durable) experience, since graphics and interaction effects that are very detailed or close to the original would not make much of a difference for users: the emotion of "being there" would not significantly increase.

Allusive, metaphorical, or illusionistic approaches - as used sometimes in theatre or in opera performances - can be emotionally more powerful: to represent the city of Venice, some striped poles marking the course of canals may be sufficient to evoke the famous city, or placing gorgeous pieces of furniture in a virtual room can allude to the interior of an old aristocratic palace. Allusive features contribute to increase the sense of psychological proximity, a concept of game theory that denotes the extent to which a situation compels users to use empathy and imagination to put themselves into the experience [82]. Some areas may be even more "virtual" than the rest, in that they are not 3D geometries around or inside which avatars can walk, but only texture images on a flat surface, creating the illusion of a house, a village, a mountain in the distance. Sometimes simply changing the "floor" texture from grass to sand is enough to switch from a field to a desert. It does not matter that avatars can walk as easily in the sand as in the grass, or that they will never be able to climb that faraway mountain, as long as the experience is designed so that they will never need or want to climb that mountain. A virtual room with a window that shows an "outside" view of a town (created by applying an image of outside environment as a texture on the window panel) builds the illusion that what is beyond the window is actually "there" (even if the window cannot be opened), with absolutely no need to actually create the 3D geometries for the town buildings.

As in theater painted curtains and background are used to give a sense of depth to the stage (and to provide quickly interchangeable settings), in a virtual space a tiled floor or a road lined by geometric buildings make it easier to perceive spatial depth and the relative position of objects and users (e.g. "that avatar is 3 squares/3 buildings away from mine"); when cleverly "painted", virtual walls can create a perspective illusion of space well beyond the actual size of the stage (as in Palladio's Olympic Theater in Vicenza, Italy) achieving a much higher sense of presence than a virtual room with walls and floors of a homogeneous color, where it is very hard to tell how far an object is or how large the space.

Still, the visual properties of the 3D digital world are only a prerequisite to achieve personal presence. What really keeps users engaged with the space and removes awareness of the physical world is what they can do in the 3DSS. How to design engaging activities is the subject of pattern 4 "What are we supposed to do?" and is discussed in details there. 


\section{Examples}

\section{Example 1: allusions}

A few, simplified architectural elements in SEE - Shrine Educational Experience (Figure 2) and in Virtual Leonardo (www.museoscienza.org/english/Leonardo/leonardovirtuale) suggest that the action takes place in the Israel Museum in Jerusalem, or in the Science and Technology Museum in Milan [9, 31]. Users who had been to the real places immediately recognized the virtual buildings when they saw them.

A medieval castle as the virtual environments of Stori@Lombardia [70] evokes a "Middle Ages" atmosphere for a learning experience on medieval history in Lombardy. Detailed modeling is not necessary, since it would add very little to the user's emotional experience.

\section{Example 2: geometric shapes: tiles and converging lines}

In project Learning@Europe [30] most rooms are round, and the striped tiles on the floors (Figure 3) give some sense of perspective to the virtual world: it is easier to perceive distance and the relative positions of objects. In some cases tiles are arranged in a way that the farthest objects appear much more distant that they "really" are.

\section{Example 3: textures}

In Learning@Europe, one of the environments in the 3D virtual world is a round room with blue walls and a domed ceiling, from whose (sealed) windows other domes can be seen. The view from an external "fixed camera" shows a red, a green and a yellow dome next to the blue one (Figure 4). Users are invited to pass through a door from the blue dome to the red one and so on. What actually happens is that the same room is reloaded with walls in a different color and the slightly different landscape that can be seen from the windows is nothing else than a texture image creating the illusion of other buildings outside the window pane. Users have the impression of exploring 4 different rooms, each exhibiting different content (again, different textures attached to panels on the walls).

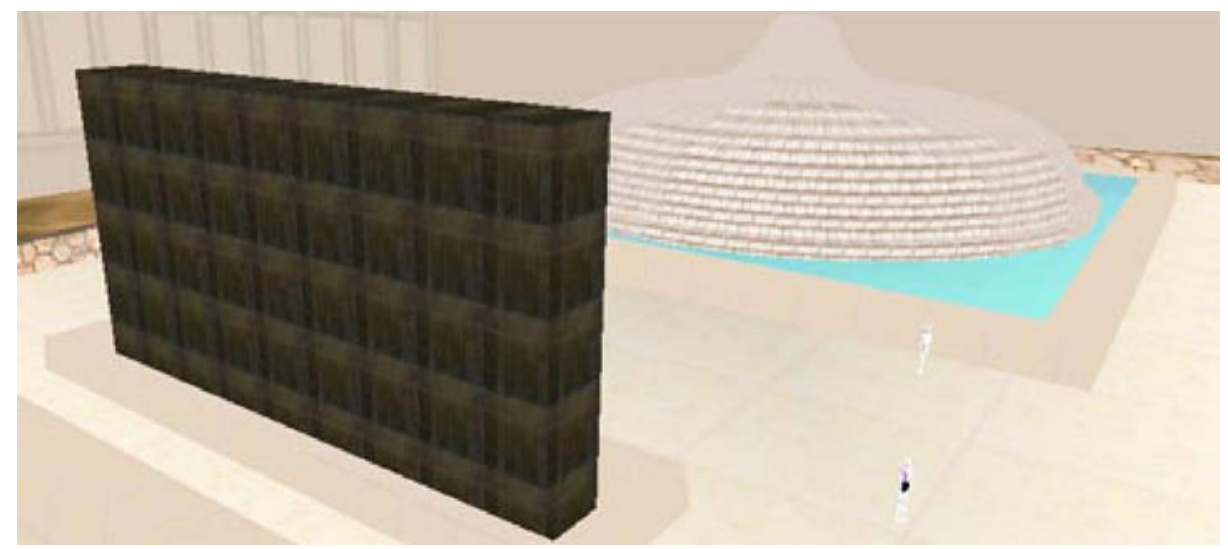

Figure 2 The virtual "Shrine of the Book": a simplified virtual version of the characteristic buildings at the Israel Museum, Jerusalem. 


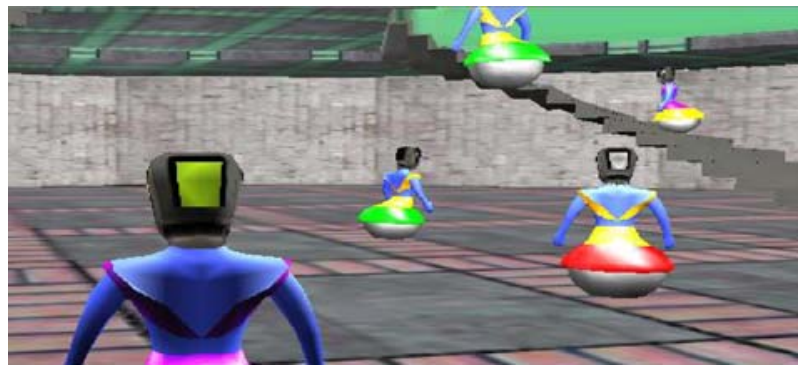

Figure 3 The striped tiles on the floor show the avatars' relative positions and create the illusion of 3D depth.

When users are expected to stay only in a restricted area of a virtual space, texture images of faraway mountains all around the "horizon line" (Figure 5) make an open space look wider than it would feel if an avatar actually "walked" up to the end of it.

Related patterns Functional to personal presence is Environmental Presence, discussed in pattern "Does The Space Feel Me". The design of activities that foster long term engagement are the subject of pattern "What Are We Supposed To Do?".

\subsubsection{Pattern 2: "Does the space feel me?"}

Context Users logged in your 3DSS are moving around the virtual space, possibly performing some tasks (not necessarily with others participating in the experience) while sitting at their own desk in front of a $2 \mathrm{D}$ screen.

Problem How should a 3D world be designed so that it appears to be aware of the users, thus fostering Environmental Presence and, through it, increasing users' feeling as they were in the virtual environment rather than in their actual physical environment (Personal Presence)?

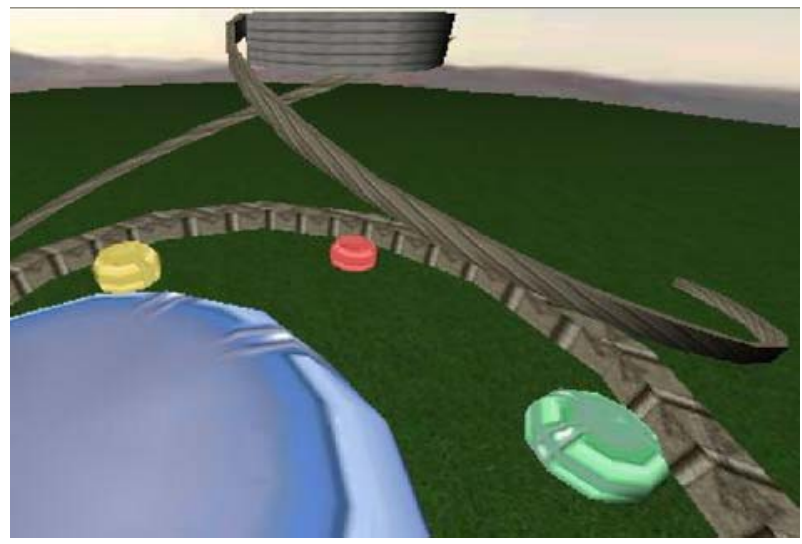

Figure 4 The view from the "fixed camera" (that can be activated from the user interface) outside the blue dome enforces the illusion that four colored domes are there, while in truth the same dome is reloaded with walls of different colors when users pass through a door. 


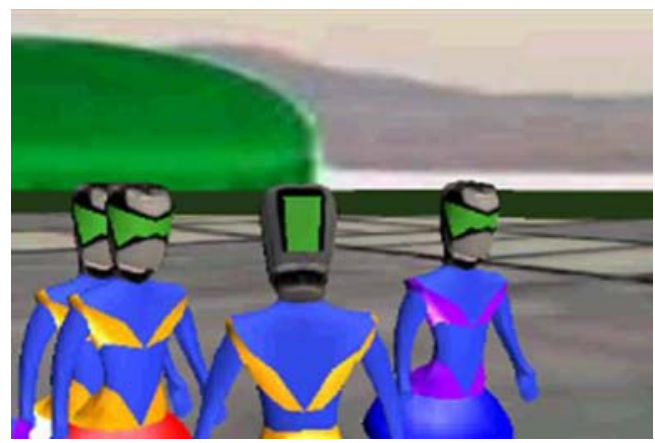

Figure 5 In the background, texture images of mountains in the distance make this open virtual space seem larger.

Forces Realistic virtual reproductions of real or imaginary locations, in terms of both the look of the space and its physical rules (e.g., gravity, lighting, objects' reaction in terms of shape, sound, movement) make it easier for users to perceive the space and "feel there". 3D modeled virtual environments that are totally unaware of users' presence and behave inconsistently with the human expectation of the environment physics may disorient the user: s/he may get lost inside, for example, a virtual valley if $\mathrm{s} / \mathrm{he}$ is not careful enough to avoid illogically crossing boundaries set by surrounding mountains. Still, high-fidelity graphics, both in terms of visual realism and coherence with the rules of classical physics, is complex to design and expensive to achieve (see also discussion in pattern "Where am I? "), often imposes high technical requirements to the final user and does not necessarily improves the feeling of being in the reproduced place. In some cases, incoherence with normal human or environmental behavior (e.g., the avatar's possibility of traversing a solid wall) may add (under some conditions - see pattern "What Are Our Super-powers?") excitement and the feeling of magic.

\section{Solution}

- Provide feedback on user tasks and behaviors, e.g., using conventional aural effects in response to some crucial user's actions, or creating special (2D or 3D) objects or visual effects that (dynamically) present a movement trajectory taken, the consequences of an activity, or a successful completion of a task, e.g., a score-counter displaying the current score and dynamically "growing" as points are gained.

- Use allusive feedback effects rather than strongly realistic feedbacks: the behavior of the environments might not necessarily be anchored to the real physical world, its goal being to create users' awareness of the space and of the effects of own and the others' behavior. For example, bell's rings might be triggered each time an avatar gets very close to a target - even if in the real world we usually do not hear bells ringing each time we reach an intended destination.

Rationale As noticed in [74], a passive, a-constrained, un-reactive space likely detracts from a sense of personal presence [46], thus suggesting that environmental presence - the fact that the virtual environment knows that users are there and manifests this awareness [95] - can enforce users' feeling as if they were in the virtual environment rather than in their actual physical environment. In addition, a virtual world which is more responsive than the real world could evoke a greater sense of personal presence than a virtual world 
where the environment responds exactly like the real world [74]. In other words, virtual worlds can also be designed to be more responsive than real worlds. When you walk into a room in the real world, it does not verbally or musically greet you. Virtual rooms might.

Proper feedbacks, even when lacking a realistic counterpart (e.g., a flying avatar steering), create a situation where users feel more engaged in the space and in the current activity and improves their perception of how the experience evolves. They supports a form of environmental presence that does not focuses on the reproduction of the behavior of a virtual copy of a "real-life place", but rather highlights what goes on in a given context, trying to put the users in the best position to perceive the digital space and "feel in the situation".

\section{Examples}

\section{Example 1: “piling up” scores}

In FATE2 project $[39,40]$, the 3DSS experience is inspired by a set of simple 2D (Flash based) multimedia fairly tales that our lab developed for primary school children and is composed of a set of fantasy worlds. Each world corresponds to a 2D story "scene"; it is populated with the corresponding scenario, characters (animals and young children, in most cases) and objects (e.g., mountains, flowers and trees) and involves learning tasks and educational games. When a child completes a game, s/he gains points for her/his team and 3D diamonds, that are visible in all worlds and represent the team score, grow (Figure 6).

\section{Example 2: allusive feedback}

In all virtual environments of our projects, in order to move from one section to another, users are requested to "cross doors" in a special, non-intuitive way. They need to run and apparently crash onto them. If they do it the in right time and in the proper way, the environment provides a feedback in the form of a sentence against a black background: "you are moving to the next ... (dome, playground, labyrinth.,.)". The black screen slightly "trembles" to suggest the idea of a mysterious travel through space.

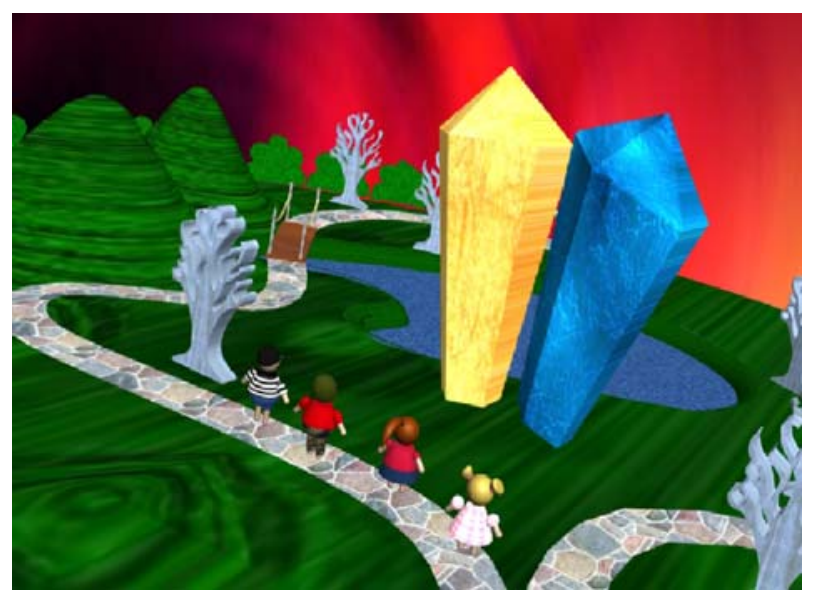

Figure 6 The growing "score competition diamonds" of the two teams in the fantasy world of FaTe2 Project. 
Related patterns Environmental Presence is functional to Personal Presence, discussed in pattern "Where Am I?". Environmental Presence is affected by the actual behavior implemented for avatars and by the degree of their superpowers, as discussed in pattern "What Are Our Super-powers?

\subsubsection{Pattern 3: "What are our super-powers?"}

Context A group of people is simultaneously located in a 3DSS and are involved in tasks that not only require to perceive the presence of the other users but also what the others are doing. Their "alter egos" in the virtual space (avatars) can have, in principle, both some "realistic" powers (walk, run, talk, jump) and some "super" powers (e.g., fly, teleport, see the $3 \mathrm{C}$ space from different points of view...) that people normally do not have in the real world.

Problem In a social context, what degree of super-power should be given to avatars, i.e., what should they be allowed to do and not to do?

Forces In 3D virtual spaces, almost all of the real world constraints can be eliminated: avatars may be able to activate links or hotspots from any location, pass through walls, fly, look at the environments from various points of view (fixed cameras and even another avatar's eyes), etc. "Super" powers contribute to enjoyment and engagement (so they are largely used, for example, in virtual games). However, if avatars can break any physical rules holding in the real space, they may lose the perception of the virtual space (reducing the sense of environmental presence). Paradoxically, if they could interact with any object in the space regardless of their proximity, users would have no more reason to move or explore the environment. The possibility of doing anything from anywhere implies that avatars do not convey any proxemic ${ }^{4}$ signals to the other users. Proxemic signals in the real physical worlds are those forms of non verbal communication that are normally conveyed by our position and posture and by our perception of the spatial distance between individuals and allow humans to guess, for example, what other persons are doing just by looking at them in the space: are they activating content, reading a board, answering a quiz, deep in conversation with someone, or simply hanging around (see Figure 7)? One possibility of conveying some proxemic signals is to notify every member of the group of any action taken by another member. This approach, however, may lead to an overload of not always useful information.

\section{Solution}

- carefully balance the avatars' powers, providing them with "super powers" whenever it is needed by the tasks in which they are engaged (e.g., in the context of a game flying may be needed), but not needlessly!

- set limits to the superpowers that avoid the necessity to move around, explore the environment, discover the presence of others participating in the experience. For

\footnotetext{
${ }^{4}$ The term "proxemics" was invented in 1966 by Edward T. Hall, an anthropologist who, on the basis of research on the spatial behavior of the animals, developed a discipline studying the culturally determined interactions between humans and the spatial environment [45]. He considered many factors: the distance between people, the spatial relation with the environment, the gaze (more or less direct), the voice's volume and even the smell and the perceptible body's heat. Proxemic semiotics is a part of the very large realm of non-verbal communication: strictly speaking, it deals with signs conveyed through space.
} 


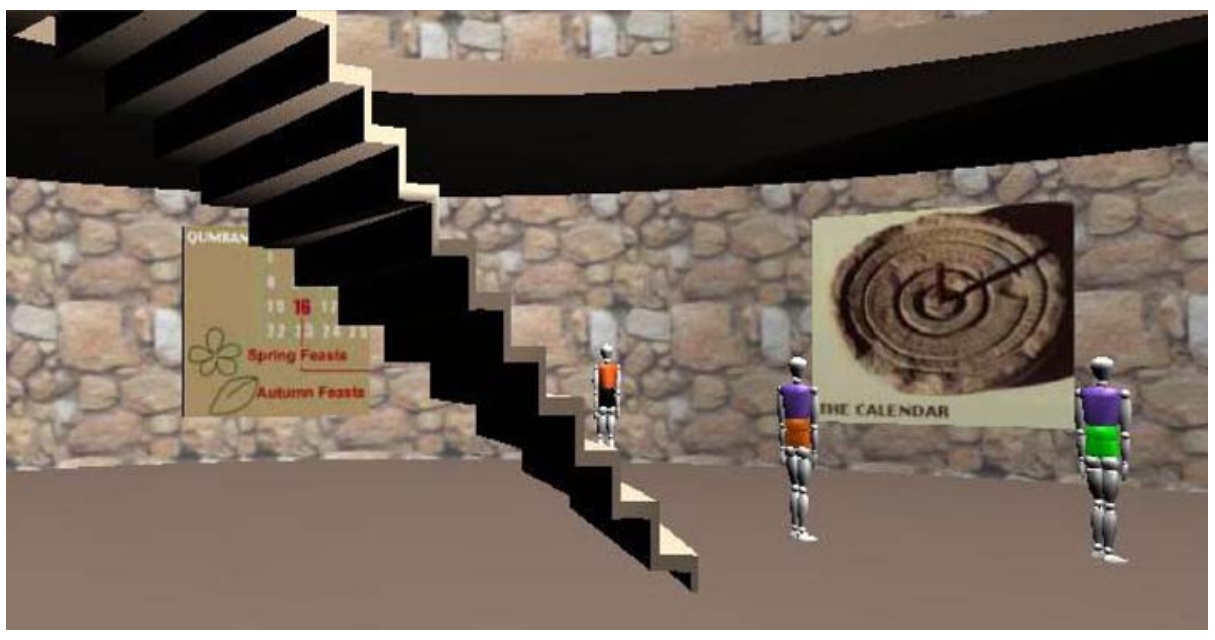

Figure 7 Avatars hanging around in the virtual environment of SEE (Shrine Educational Experience) What are they doing: looking at the nearby board? Chatting together, or with some other user? Listening to the tutor's lecture? Exploring the environment? Just hanging around?

example, avatars should be able to interact only — or mostly — with objects or users in their proximity: if interesting items are scattered around the environment, users will need to move in order to reach a desired object

Rationale Constraining superpowers so that some intuitive physical rules of the real space are preserved in the virtual space increases the sense of environmental presence. Limiting superpowers so that users are forced to move their avatar around in order to interact with objects and peers motivate them to explore the environment and increase their opportunity to meet the others and ultimately engage in cooperation activities. Still, providing superpowers when needed to perform a task increases fun and excitement, making the experience more engaging.

Creating proxemic signals in the virtual space that re-interpret what in the physical world is normally conveyed by our position, posture, or mutual distance among individuals improves social presence: it makes much easier and more natural for every user to perceive the others and to know what the avatars around are doing (see Figure 7).

The existence of proxemic signals also affects effective collaboration: various studies report that unplanned, casual interactions between small groups that arise from informal awareness - including non-verbal communication enabled by proxemic signs-prove important for collaboration $[50,61,91]$, but casual interactions are severely affected by physical separation.

Examples In the 3DSSs developed at our lab, we set limits to the avatars' powers with the purpose of saving proxemic signs. For example, in order to be teleported from one environment to another, avatars have to pass through a door (Figure 8: they run, "bump" into it and the new environment is loaded): usually, it is the tutor that invites the participants to follow her/him and run as fast as they can. This "crowd-movement" immediately tells stray avatars what is going on; in addition, it creates the feeling of really passing from one place to the other. Another example regards the activation of content (pop-up windows 


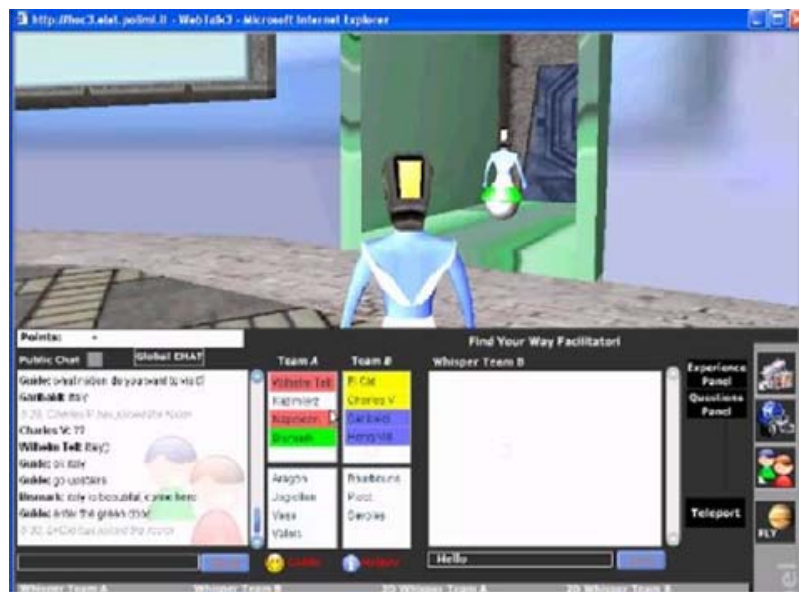

Figure 8 In order to be teleported from one environment to another, avatars have to run and "bump" into a door: this movement tells all the other what is going on.

containing text, images or video) from hotspots within the 3D space. If an avatar wants to activate a board (which is clearly visible in the environment-Figure 9) and see the attached content, it has to be close to it. In a similar way, if a user wants to whisper with another user (i.e. to address that user and not all the users), the two avatars must be close to each other.

In Second Life, when someone is typing a message in the chat, the avatar makes a typing gesture and a typing noise is heard, thus saving the proxemic sign. This alludes to what normally happens in real life: when a person is speaking, everyone can hear the voice and see the lips moving. Knowing who is taking the next conversational turn is so important that in many Instant Messaging systems, even without an avatar, users are notified when somebody is typing a message to them (but hasn't sent it yet).

In order to preserve proxemic signs, in many virtual worlds - especially large onesavatars can only interact with objects and characters if they are close to them. In Second Life, for example, to take part in a conference, concert, or other virtual event, an avatar

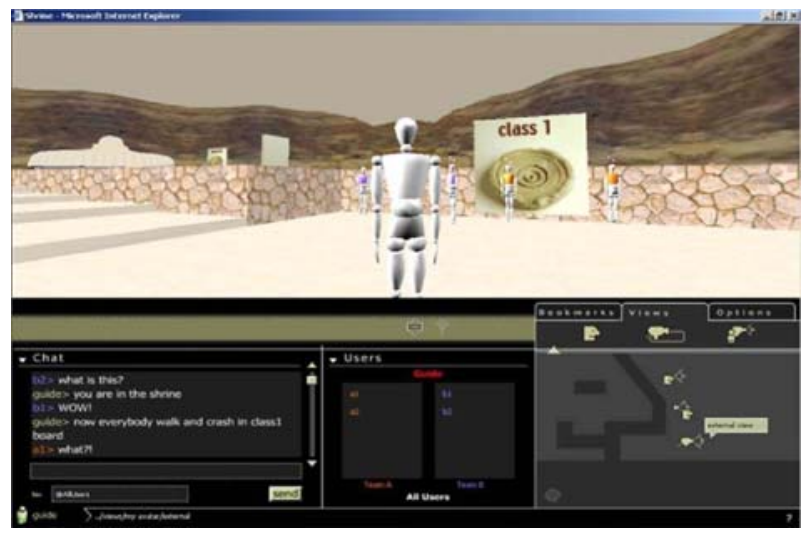

Figure 9 In order to read the pop-up content attached to a board, avatars have to be close to the board. In this way, all the other users can know what one is doing. 
needs to be in a certain designated area (often with rows of seats). In many games, in order to collect an object or fight an enemy, the player must usually get close enough to it; a person can only "eavesdrop" messages "spoken" around her avatar (although it is often possible to "page" known users whose avatar is somewhere else in the virtual world).

Related patterns The design of a proper behavior for avatars affects social interaction and mutual cooperation, which are addressed from a broader perspective in pattern "Shall We Do It Together?"

\subsubsection{Pattern 4: "What are we supposed to do?"}

Context Users are taking part in a 3DSS experience that need to involve them over a prolonged period of time.

Problem How do I design activities in a 3DSS in order to keep multiple users engaged in the long term, involving voluntary, repeated use of the system for more then few minutes, across days, or even weeks or months?

Forces Interacting with a 3D world and with other remote users can be fun per se, but engagement does not always happen spontaneously: after the initial excitement for "the new thing", users may give up unless they find something interesting to do. In addition, even if users like social interaction with other users per se, spontaneous conversations are often shallow and not very meaningful, and they may quickly become boring.

Solution In order to keep users engaged in the long term in a 3DSS, it is advisable to:

- provide users with clear, focused and appealing goals/tasks. Each activity must be meaningful and users should be interested in the result (or at least in the process)

- $\quad$ keep the action fast-paced, avoiding void moments and long suspension of activities; at the same time, allow for some breaks of appropriate length so as to leave space for either autonomous exploration of the environment or spontaneous interaction with other users;

- challenge users, so that they feel stimulated by to test themselves. To be "sufficiently" challenging, the tasks proposed to users should match their skill level without being discouragingly hard or boringly easy, require a progressive level of skills unlocking new opportunities along the way. Offering activities that involve competition can increase challenge;

- provide some gaming situations;

- structure interaction carefully as a well organized workflow of activities, so that users are always given something to do; this avoids the risk of having lots of users hanging around, in the best option chatting about trivial matters and quickly losing interest in the experience. The workflow of activities, although focused and well structured, should be sufficiently flexible in order to accommodate the needs of different user profiles and goals for the experience;

- guide interaction, to avoid users distracting other users or hindering them in their tasks, e.g., by means of an online "tutor" or "experience guide"

- stimulate social interaction, for example by means of an online moderator who invites users to get involved in discussions and social activities, provokes them with questions or challenges, or introduces new topics to add new elements to the experience. 
Rationale Depending on how long you plan your users to be around, what their goals and expectations are and what kind of experience you intend to offer, actions in your 3D world can be loosely or tightly structured, offer one or many possible paths, involve simple or sophisticated interaction with other characters, objects, and the digital environment. Whether the driving force is competition, gaming, informal interaction, or some extrinsic purpose, the essential element is to make sure that users always have one or more goals that they want to achieve and some help or some idea of what to do in order to achieve them.

Designing fast-paced actions through proper stimuli keep the user's concentration, so that the person's attention is completely absorbed by the activity and all relevant skills are employed in it. Concentration is a component of the Flow State [26] and, ultimately, contributes to engagement.

Games create emotionally driven situations that foster fun, which is fundamental to maintain engagement along the time $[13,26,55,63,66,82]$ As suggested by many game theories $[55,63,82]$, fun is a crucial driver to create an intrinsically rewarding experience that user may will to repeat and continue along the time.

For many users, testing their abilities and overcoming obstacles creates emotions and rewards. Challenge helps users to focus attention, inspires creativity and fosters the development and application of skills or strategies. Competition is a way to create challenge and adds emotions that make an experience (not necessarily a game) more exciting and joyful [87]. Most people (youngsters in particular), gain satisfaction from competing against and beating other people.

Finally, social interaction is a powerful motivator for people to engage in a virtual world experience both in the short and in the long term. Talking with remote peers or participating in collaboration activities, increase the sense of "being connected", promotes a sense of "community" and social identity among participants in the same session of use of a 3DSS, enforces the feeling of self-recognition; it is a way "to make thinking visible" and to create a more tangible context for what is being experienced. Still, social interaction may not spontaneously occur nor flow properly: it might need to be stimulated and moderated. People may be shy, or do not understand why they should do something with others. Sspontaneous conversations are often shallow and not very meaningful, and they may quickly become boring or they may take outrageous forms (e.g., using offensive words). A person "from outside" can redirect conversation and social activities towards the proper directions, fostering for example intercultural exchanges, discussion over a debatable issue, etc.

Examples We shall present two examples: the first is about a gaming environment in Second Life where users take part in (individual) gaming activities. The second is taken from 3D based educational experiences where users (in groups) take part in a structured set of activities. In this last case, meaningful social interaction is fostered by online tutors.

\section{Example 1: the "Theme Park" in Second Life}

In the frame of the Learning@SocialSport project, a "Theme Park" in Second Life was created (Figure 10). It was conceived as a purely playful space where the project would be advertised (boards on the wall describe the project, link to the official website, show pictures of the project's participants...). In addition, the "Theme Park" can also be used to raise interest in a specific subject matter (in the case of the Learning@SocialSport project, sport disciplines like volley, basket, etc.), since users are encouraged to look for information on it as a means to answer the quizzes (Figure 11).

Basically, users of the thematic park are expected to enjoy themselves by playing with two interactive machines: a sort of slot machine (nicknamed "sport-machine") and a 


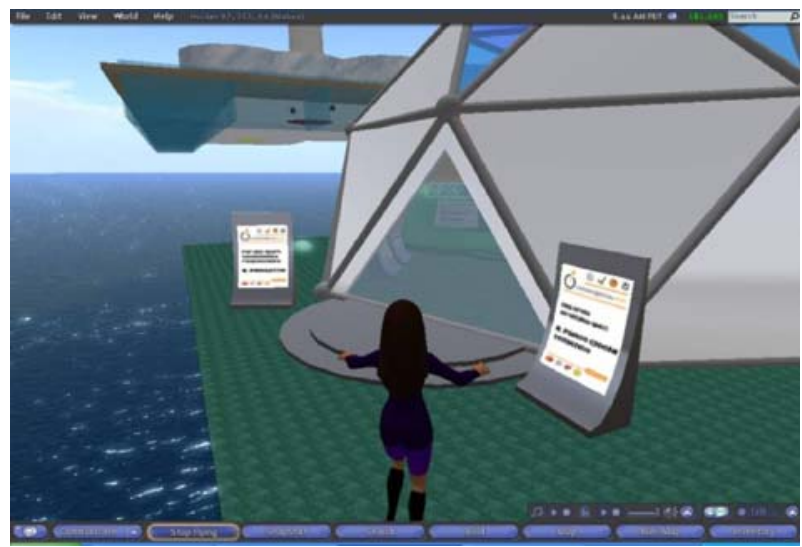

Figure 10 The "Theme Park" of Learning@SocialSport in Second Life. Boards at the entrance advertise the project.

memory game, both connected to sets of multiple-choice quizzes on various sport disciplines.

Each month the theme of the theme park changes, shifting from a sport discipline to another. Two kinds of competition are offered: the "one day" competition, crowning the best performance of the day and the "one month" competition, crowning as winner the user who piles up the highest score.

As suggested above in the first set of solutions, the theme park provides users with a sequence of activities (the games) and with clear, challenging goals (I can compete either against myself, pursuing my personal record, or against others in the competitions). In addition, it is very fast-paced: users have a very limited time to perform the games and to answer the questions, which is not enough for them to even search the answers on Google.

\section{Example 2: HOC-LAB's 3D-based experiences storyboard of activities}

Since the very first of our 3D-based educational experiences, we decided to sketch a very precise storyboard of activities, which we refined year by year (Figure 12).

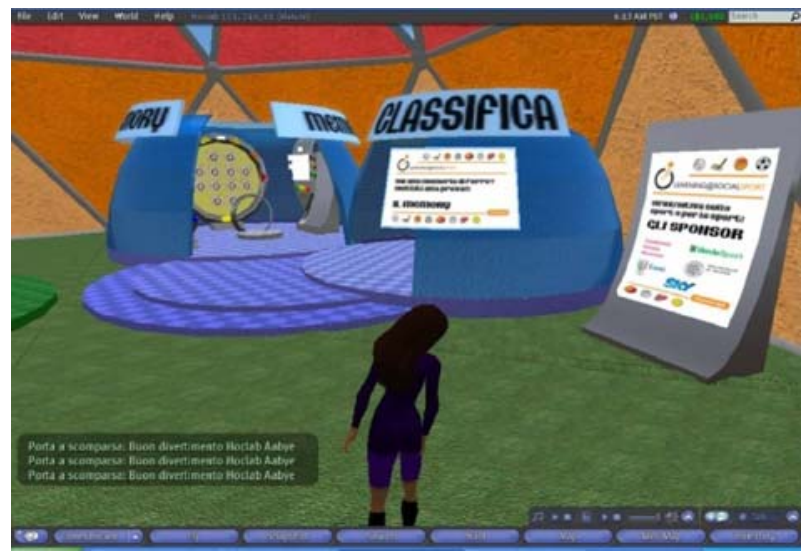

Figure 11 The "Theme Park" of Learning@SocialSport in Second Life. An avatar approaches the memory game (in the blue little dome on the left). 


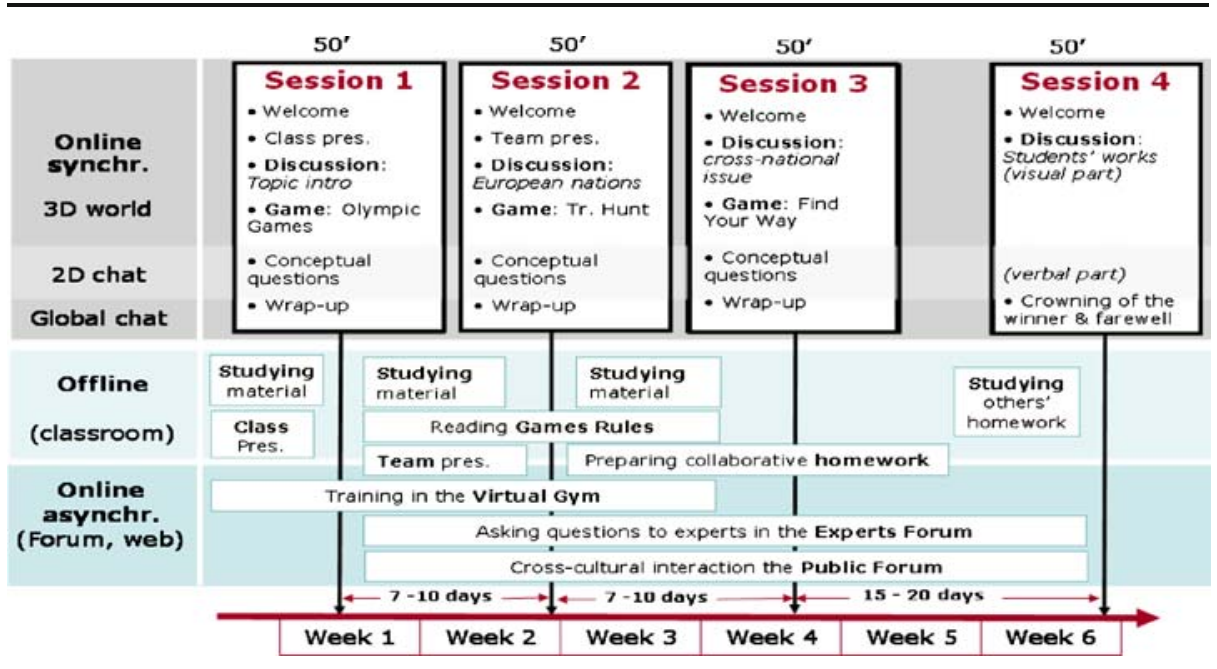

Figure 12 The Learning@Europe storyboard of activities.

As it can be seen (Figure 12), there are two main kinds of activities: online activities (the core of which are 4 meetings or "sessions" in the 3D world), both synchronous and asynchronous, and offline "traditional" activities in the class (like studying the background materials, working on assignments, etc.). Taking a closer look, each online session also has its own storyboard: for example, session 1 begins with a welcome phase (in which an online tutor introduces the overall experience and the $3 \mathrm{D}$ environment), followed by the participating classes' presentations (each taking place in a different room in the virtual world-Figure 14). Then the topic of the session is discussed, with the help of visual aids. The first game kicks off the competition (Figure 13). Conceptual questions test the participants' background on the subject at stake (European history) through all the sessions. Eventually, during the final wrap up, assignments are given for the next meeting (Figure 14).

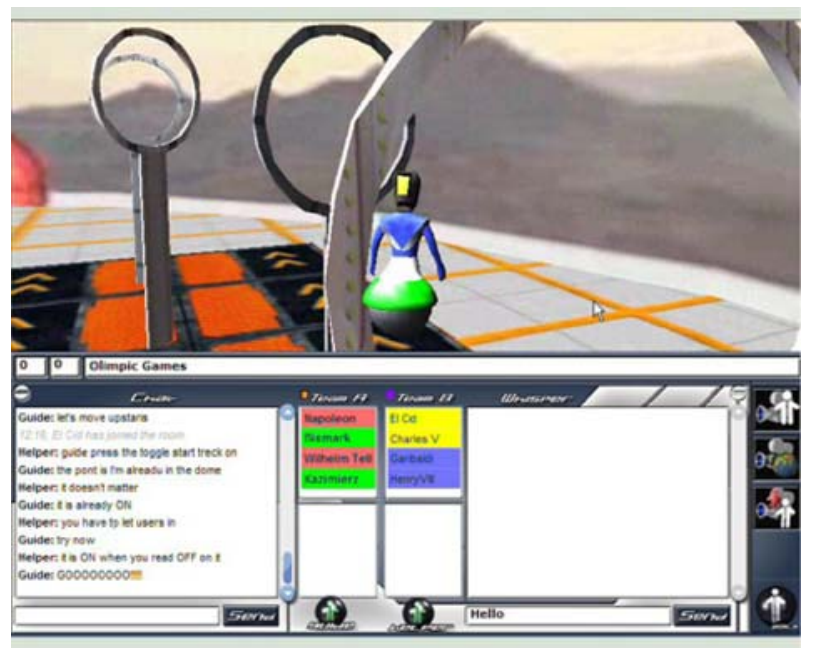

Figure 13 The "Olympic games" (playful ability games, such as flying through circles) break the ice and kick off the competition during the first session of Learning@Europe. 


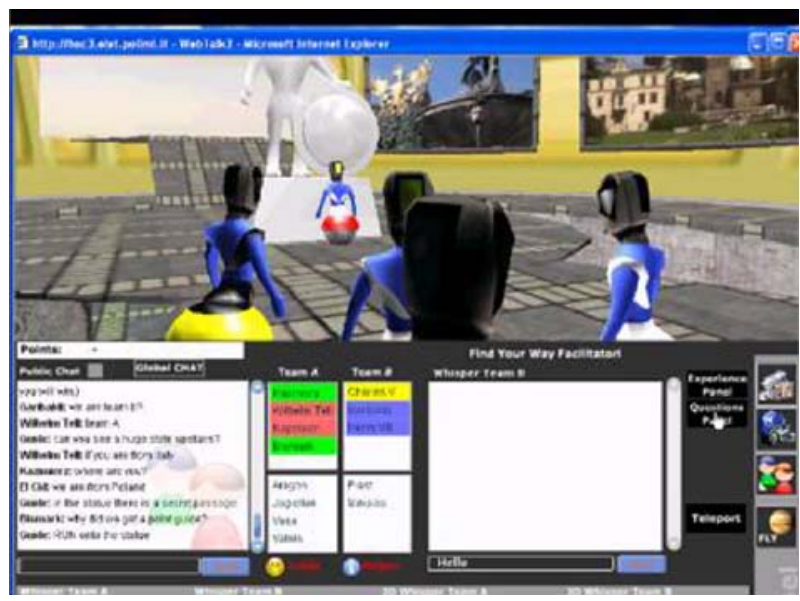

Figure 14 Avatars show pictures of their class, town and country in a dedicated room.

3D sessions are managed according to their storyboard by two online tutors, whose roles respectively are (1) to guide the users in the 3D world, activating hotspots, refereeing the games, assigning scores and (2) stimulating and moderating the cultural discussion.

As the reader can see, both the macro and micro storyboards of HOC-LAB's 3D-based experiences fit the proposed solutions for fostering long term engagement: there is a sequence of activities; each game/activity has a distinct goal, while also clearly contributing to the larger goal (winning the overall competition). The online tutors keep the action fast paced (oftentimes students complain when the tutor, after an hour or more, announces that the session is about to finish: they say they had not realized time was passing so fast...). However, some moments are left for autonomous exploration of the environment and spontaneous interaction. Finally, it is the online tutors' specific duty to moderate and if necessary stimulate interaction and discussion on cultural topics.

\section{Other examples}

In many online multiplayer games based on 3D virtual worlds, after a short exploration the user meets a computer-generated character that sends her on a quest ([8]). Video and console games often begin with a cut scene (a sort of movie sequence which the user can only watch) that introduces the "characters", sets the "story" and sends the user on some mission. While trying to complete the quest, the player encounters other challenges or collects additional quests, so that s/he's never lacking something to do; as quests are completed, the user gets stronger: new powers are acquired, new possibilities open up and new goals emerge, keeping the game interesting and the user busy even for several months. Clear goals, a clear sequence of activities in order to fulfill them, challenges and fast-paced action - as described in the pattern's Solution - are all essential in creating and maintaining engagement.

Social virtual worlds such as Habbo, Second Life, Active Worlds [1] and similar are less structured: basically, people connect to interact with other users. Those not really interested in interacting with strangers might get bored quickly, unless events are organized (e.g. a virtual concert, meetings held by special interest groups) to stimulate and lead interaction.

Related patterns Transforming one of the engagement factors - social interaction-into effective collaboration is a complex issue, addressed in pattern "Shall We Do It Together?". 


\subsubsection{Pattern 5: "Shall we do it together?}

Context A group of people takes part in a 3D-based experience as a team and need to collaborate.

Problem How can a 3D-based synchronous multiuser experience be designed so as to foster effective cooperation?

Forces Effective cooperating with remote partners can be very exciting, in the discovery of mutual similarities and differences, thus motivating users to continue the interaction and is a powerful spur to do one's best. It is also extremely valuable in terms of learning, in that it provides a context for the social negotiation of meaning [88].

On the other hand, the fact that a number of users $\log$ in a shared multiuser space online at the same time and "feel" the others does not necessarily mean that they will spontaneously engage in collaborative activities, or will not be tempted to give up, for a number or reasons:

- by its very nature, cooperation requires all the actors involved to participate, keep pace, be active. If one of the actors involved does not show up or is particularly uncooperative, this negatively affects the rest of the group;

- remote collaboration poses new challenges in addition to those of face-to-face collaboration: users need extra motivation, since talking to each other and working together through a virtual tool comes less natural than doing the same with people physically present and can be more cumbersome and more demanding; the presence of collaborators face-to-face involves a certain amount of social control that is missing in a remote situation (when others are present, one doesn't usually do something else or leave the room without notice while the group is working together);

- when the number of users who are simultaneously present in the shared virtual space is large, it is difficult (conceptually and technically) to orchestrate activities so that all users do something together. If an activity is sized for a limited number of collaborating users, the risk is that the "others" in the team get bored or frustrated and give up.

Solution Cooperation can be enforced if the experience is designed so that:

- there is an overarching shared goal for the whole experience that is clearly stated to all participants and is perceived as desirable, strongly motivating, intrinsically rewarding so that the perception of effort is reduced

- the shared goal can only be reached by means of cooperative rather than individual activities

- the cooperative activities are carefully planned and distributed all along the time, splitting the overall goal into "bitable chunks" of more affordable shared sub-goals and providing an array of different, progressively complex collaboration activities;

- tasks are linked together and carefully orchestrated, so that the success of one user's task affects - some way or another-another user's task;

- $\quad$ users are involved according to their personal profile: Different roles must be devised so as to allow people with different skills, abilities, potentials, preferences to actively contribute to the common end

- activities that require the collaboration of a subset of a team do not impose a long suspension to the others: those who are not involved are not forced to wait inactively 
"until others finish something", but are enabled to continue experiencing novel activity details.

Rationale The concept of "overarching goal" in a 3DSS experience is directly analogous to the concept of a "mission" for a social structure (being it an institution, a company, or a large organization) which describes what is unique and special about that structure, what it stands for, what people involved with it (e.g., employees) could focus on, should strive for, and use as a guideline ${ }^{5}$. An overarching goal has several important effects. It builds a common frame of reference that allows people with different backgrounds and varying orientations to pull collectively towards the same ends. It is an important force for community building and for creating collaboration attitudes. It is highly motivational: it places individual tasks within a larger framework, thereby giving each individual action greater significance. The more each individual perceives that $\mathrm{s} / \mathrm{he}$ is fundamental for the achievement of an overarching goal, the stronger will the above effects be [4]. People need to feel that one's successful performance is crucial for the whole group's success, which is a means to develop social commitment and team spirit. When the shared goal can only be reached by means of cooperative rather than individual activities, it becomes more clear that there is the need for active involvement of more than one person and for complementary skills and knowledge; thus persons can better acknowledge the mutual benefits of working together.

But an overarching goal needs to be translated into lower level, more concrete goals that people can more directly satisfy by means of tasks they can undertake. Thus a carefully planned workflow of activities that are consistent with the overarching goal and its subgoals must complement the goal definition itself, so as to lead participants step by step to achieve the ultimate goal, possibly though a set of trials-and-recoverable-errors. The more activities are interdependent and coordinated, the more evident the need for collaboration will be.

Involvement in orchestrated common tasks requires all the actors involved to participate, keep pace, be active. By working on a common task, users can get a number of benefits in the ethical and affective sphere, like increased social commitment ("my task is important for my community"), sense of responsibility, understanding of deadlines, capability of working in groups and negotiating with peers.

Providing an array of different, progressively complex collaboration activities trains the participants in their gradual discovery of how remote cooperation works and helps avoiding discouragement in the case of failure ("this task did not go well, we can do better in the next"). It creates a challenge that is intrinsically rewarding for users (as discussed also in patter "What are we supposed to do?"). Balancing complexity and tasks assignment according to participants' profile (e.g., abilities and preferences) facilitate each participants' commitment to collaboration, increases satisfaction and reduces the risk of frustration.

\section{Examples}

\section{Example 1: winning a competition as overarching goal}

All the 3DSS experiences developed in our projects are designed in view of fostering cooperation in a number of ways. We organize users into two teams and propose a

\footnotetext{
${ }^{5}$ IBM, for example, has as its overarching goal "customer service" (http://www.ibm.com/us/en/)
} 
competition, so that winning it is set as overarching goal of all the experience's activities. Anything users do implies winning/losing scores: in the end, the team with the highest score is crowned as winner.

For example, let's take again a look at the storyboard of Learning@Europe (Figure 12). Participants are required to take part in 3D technology-based and more "traditional", online and offline, activities. Scores are gained or lost in both realms: in the 3D world, scores are gained by winning ability games (Figure 15), answering to quizzes, but also actively taking part in the cultural discussion. In the $2 \mathrm{D}$ chat scores are gained by providing in-depth answers to difficult open-ended cultural questions. Eventually, scores are gained thanks to the various assignments. Scores can also be lost, in particular for misbehaving during the online sessions or for using offensive language in the chat or in the forum. The winner team is crowned during the last session (see Figure 16).

\section{Example 2: emphasizing cooperation in gaming: the treasure hunt}

The treasure hunt is designed so as to make participants cooperate in couples. Boxes are scattered in a labyrinth (Figure 17): once activated, they reveal a piece of content relatedor non related - to the subject at stake (ex. Polish history); once a user finds a box (step 1 of the game), s/he has to call via chat one of her team mates, asking for advice. Advice is given thanks to a rather weird technological feature: the second user can look through the first avatar's eyes, as if s/he was her/him, without the need of actually reaching her where she is in the labyrinth. If both users agree that the piece of content is correct, they have to jointly click on a button. Every "object" is associated to a piece of a sentence that appears on panels in the middle of the labyrinth when the object is selected (by a player) and confirmed (by a team mate). When all the correct objects are selected, the complete sentence appears and the game is won. Therefore it is only by cooperating, at micro and macro level, that the whole activity can be performed successfully.

Similarly, in many massive online multiplayer games, such as World of Warcraft and EverQuest, some goals can only be achieved by a group of players uniting their strength. For example, some particularly powerful enemies cannot be defeated by one single player: different users must get together in a raid in order to have a chance to win. This highly increases the excitement [64].

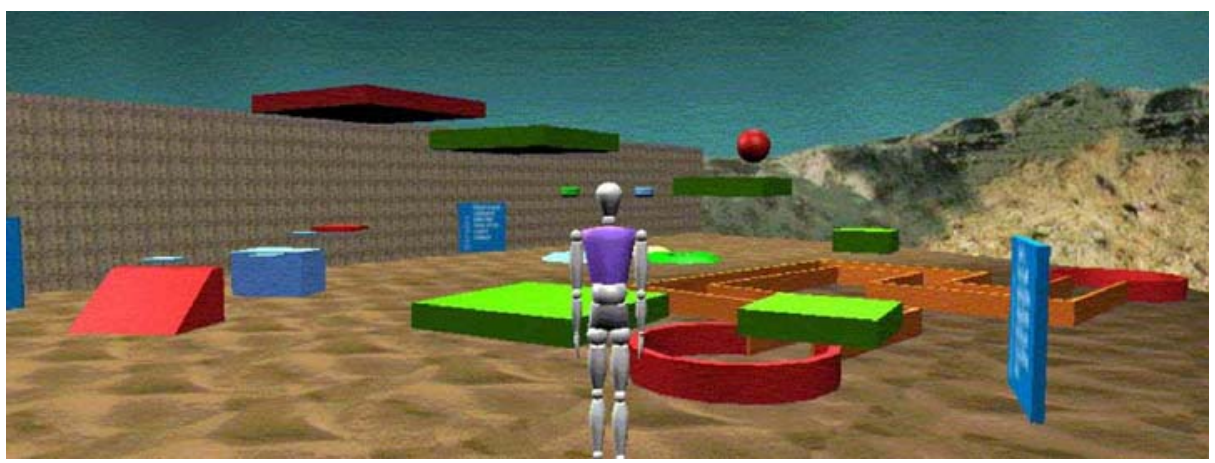

Figure 15 By well-performing in the "Olympic Games" participants can gain scores for their team (in the picture, the SEE project playground: the avatar has to jump on all the platforms). 


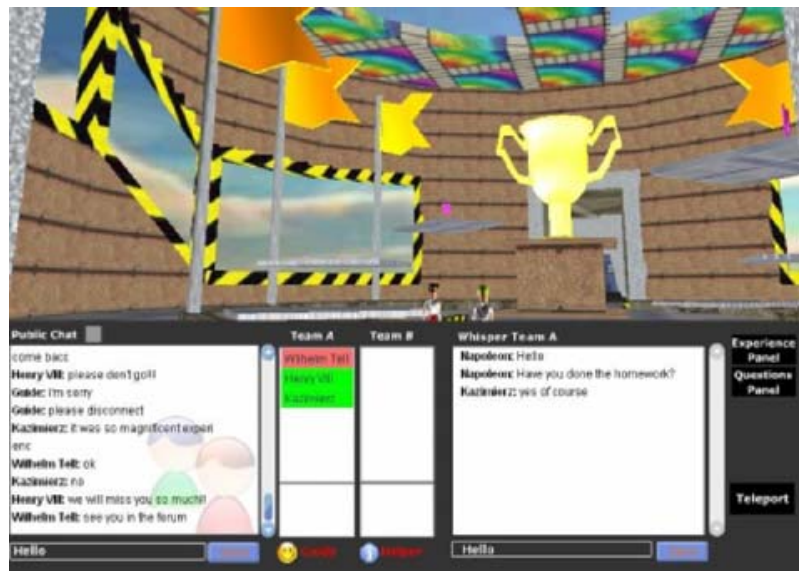

Figure 16 The winner's golden cup (Learning@Europe, fourth and last session).

\section{Example 3. Splitting activities into bitable chunks: the storyboard}

The storyboard of the activities discussed in pattern "What are we supposed to do?" (Figure 12) proposes a set of progressively complex tasks in all respects: ability games become more sophisticated, assignments more demanding, etc. Still, an unlucky performance, a cultural gap or failing to complete one of the assignments (e.g. the class' presentation) may just hinder but not forbid the successful accomplishment of the experience (and winning the competition, which is open until the very end!). In this way, students never loose their spirit: instead, they feel pushed to do their best to recover.

\section{Example 4. Linking tasks together: the "Find Your Way" game}

In the "Find Your Way" game, one player has to go through a maze full of obstacles (Figures 18 and 19) invisible to her/him, but visible to a remote peer that has to give her/ him directions via chat. If, in the cultural discussion that takes place in a parallel "2D"chat, a team mate gives correct, in-depth answers to difficult cultural questions, then a bonus is granted to the "blind" runner, who suddenly sees at least some of the obstacles in the maze and can thus speed up the race (Figure 18).
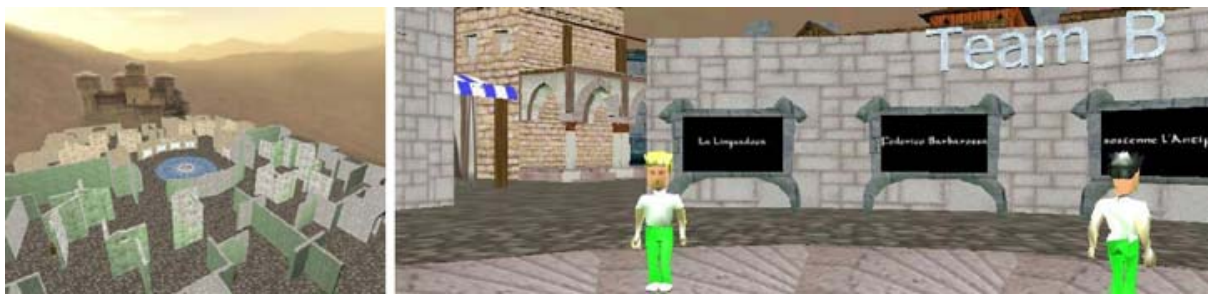

Figure 17 The Treasure Hunt Game (Stori@Lombardia): users look for boxes in a labyrinth (left); once a box is opened, it reveals a piece of content related - or non related - to the subject matter; only the joint action of 2 users allows selecting the correct piece of content, thus contributing to the formation of a sentence in the middle of the labyrinth (right). 
FIND YOUR WAY GAME

TEAM'S DYNAMICS

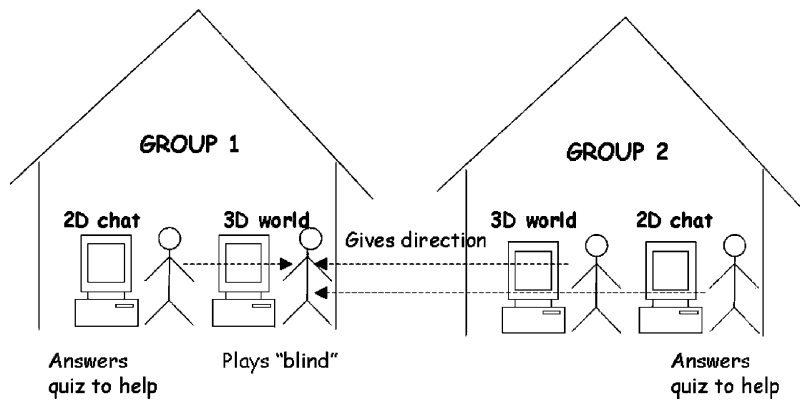

Figure 18 The cooperation lines of "Find Your Way". One player moves blindly in a maze full of obstacles; her/his remote team mate - who can see the obstacles - provides directions via chat. If the $2 \mathrm{D}$ chat players give right answers to difficult quizzes, obstacles appear so that the blind walker can speed up the run.

Example 5. Encouraging participants to exploit their own potentials and skills: the cooperative assignment

In the final assignment envisioned in the workflow discussed in pattern "What are we supposed to do?" (Figure 12), participants are encouraged to take part according to their different skills, preferences, proficiency level etc. The two remote groups that compose a team are required to produce a set of joint documents to be discussed during the last online meeting.

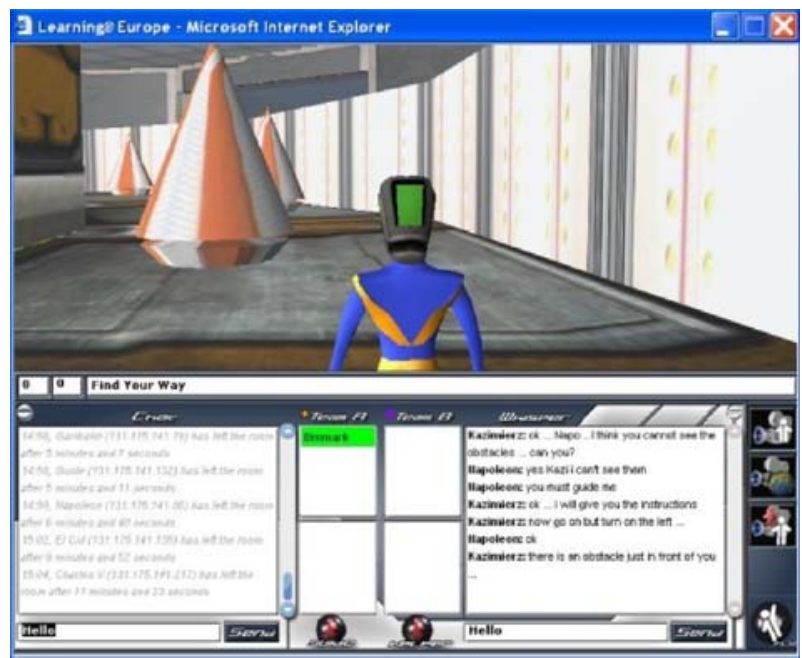

Figure 19 An avatar tries its luck in the "Find your way" maze. In the picture, we see the view of the remote player who gives directions to the "blind runner" via chat: the obstacles - big striped orange and white conesare visible to the remote peer but not the avatar that moves in the maze. 
In the last and more refined version of Learning@Europe's final assignment, these reports are based on a set of three different activities:

- interviewing at least 20 people on national symbols, identity, heroes, events, in order to test people's knowledge of their own country's history and tradition. The interviews' results must be summarized in a brief report and compared with those of the remote team partners (Figure 20);

- taking pictures of one's own town's most important monuments, streets, historical palaces and landmarks and comment on them (e.g., "why are they important?" "What happened there?".);

- making a research over a complex historical question (like for example "what role played religion in the formation of your own nation-state?"), preparing an essay and eventually comparing one's answer with the remote team's answer (thus for example comparing the different/similar role religion had in the formation of two different nation-states).

As it can be easily seen, splitting the final assignments into three different activities helps teachers in the class to better divide the work among the pupils, according to their proficiency, learning styles, preferences etc. This approach echoes the Jigsaw Classroom (www.jigsaw.org): a cooperative learning technique that fosters collaboration among groups of students by providing a common overarching goal (passing a test) and splitting tasks among students, so that they can only succeed if they help each other and rely on the information researched and presented by each of them. Every member contributes to the "puzzle" according to her/his own capabilities. Less proficient students profit from the more proficient ones who on their turn learn that everyone's contribution is crucial to the common end.

\section{Latvia and Poland's Unity Through Centuries}

The whole or partial Latvia's territory historically and politically from 15,1 ah $\mathrm{c}$ to 18th c. was in the Poland's - Lithuania's state's terntary (Żelpospolite) and in it's influence sphere.

That means also strengthened Catholicism spreading in Latvia's territory from

(You saw the Catholic Church in tean B previous homework)

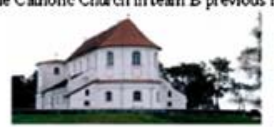

The Baltic Sea Role

Both countries geographically are located at the Baltic sea and trade sea rouses and land routes to the Baltic sea ports also developed these both regions economically and furthered their culture and information exchange (you saw one of the major routes and furthered their culture and infor

in team B previous homework

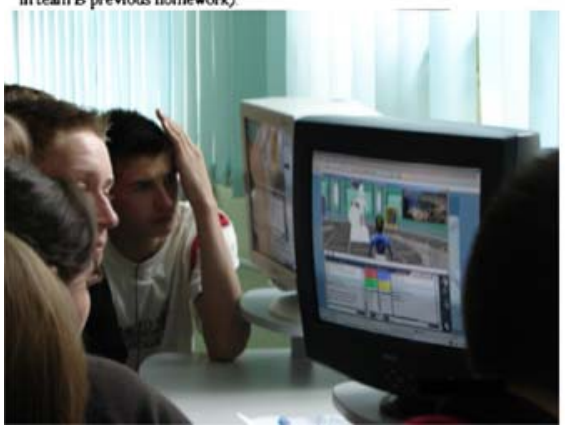

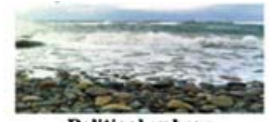

Political sphere

Both countries at the same time lock a part in socialism distraction Latvia Peoples Front lexned a lot from the Polish Trade movement "Solidarnose"

Both countries approximately at the same time transferred to the market economic, freed from USSR occupation amy and on 1 May 2004 accessed Duropean Union; also they are actively evolved in NATO.
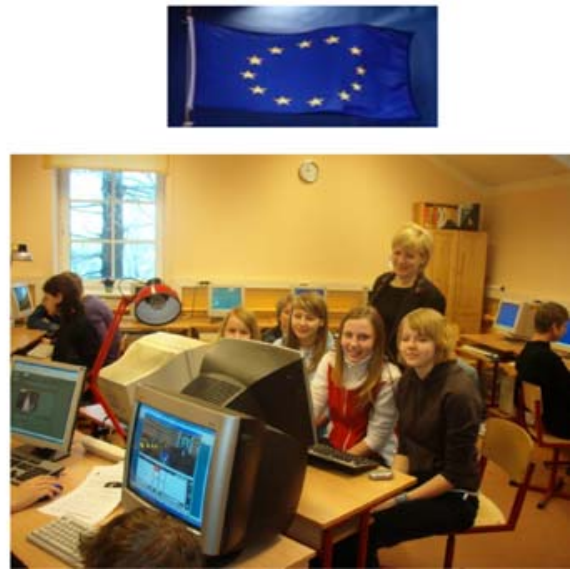

Figure 20 An example of cooperative assignment (first two pages): Polish and Latvian students (below) compare their national histories in Learning@Europe 2006-07. 
Related patterns Effective cooperation with remote partners promotes engagement in the short and long term. Further suggestions to achieve long term engagement are discussed in pattern "What Are We Supposed To Do"? (which, among other elements of the solution, also pinpoints the role of competition). In addition, to facilitate cooperation it is crucial to carefully design the actual capabilities of avatars with respect to the interaction with the virtual space and the proxemic signed conveyed to others, as discussed in the pattern "What Are My Super-Powers?".

\section{Discussion and conclusion}

Our approach to the design of 3DSSs regards this class of multiuser web applications as quintessentially "Web 2.0", focusing on the aspects that directly affect the user "relationship" with these environments, her/his role as participant to create the quality of the experience and the social dimension of this participation.

In the current state of the art, the design of 3DSS applications as participatory experiences has been largely addressed in an a-systematic way, probably since most designers of this kind of applications lack the methodological background of other communities that operate in more mature application fields and have a longer methodological tradition. It is interesting to notice how history repeats itself also in this case. For a significantly long (for computer science) period, the web design was considered a matter of creativity to be left to graphic designers or interaction designers: only a number of years after the web boom, academia and industry acknowledged the need of systematic approaches for mastering the complexity of the web design process (thus contributing to the birth of Web Engineering as a discipline). Now we are assisting to the phenomenon of millions of users who have used at least once in their life a 3DSS and of thousands of profit and non profit entities and companies that use Second Life to promote their brand, and we leave, once again, graphic designers or interaction designers dominate the methodological arena (together with psychologists and sociologists).

Besides their business potential, 3DSSs quite clearly represent a domain in which Web Engineering (WE) can and should have a scientific significant role-while also benefiting from this involvement. In the methodologically virgin field of 3DSSs, even WE basic principles (e.g., "separation of concerns") is largely unknown and there is an enormous space for exploiting WE approaches. On the other hand, applying such approaches to the specific requirements of 3DSS applications might not be straightforward; understanding the complexity of this novel field in its peculiar characteristics is a challenging goal, can highlight new issues to investigate and stimulate new trends of design research for the WE community.

This paper represents an attempt to implement the above vision, by means of design patterns that we regard as tools to achieve two main goals:

- Improvement of design quality: an inexperienced designer using good quality patterns potentially produces a better design than s/he could obtain without adopting any pattern, since they provide a "reference model" that guides design and enables a designer to compare her/his solution to existing ones of acknowledged quality;

- reduction of the time and cost of design. With the same arguments used above, we expect that an inexperienced designer, using a good library of patterns, should be able to complete her/his design with less time and less cost than it would be otherwise required. 
We are convinced that patterns as a design medium have a high potential for adoption in 3DSS arena. The 3DSS design process requires, even more than in other fields, a participatory approach that synergistically involves a heterogeneous group of specialists with a wide variety of backgrounds also outside web engineering. In this context, a common ground is difficult to build, making communication within a design team complicated and time-consuming. Patterns bridge theory with empirical evidence and tacit knowledge of experienced practitioners using a language that end users, graphics designers, interaction designers, web engineers, and business people can understand. Since design patterns have a number of standardized properties common to many fields, they can provide a shared conceptual framework for all stakeholders involved in 3DSS design-a precondition to support the participatory, multidisciplinary nature of this process. In addition, patterns are neither a prescription nor a set recipe: "creative people" do not like prescriptions! They guide designers to act in a certain way, bringing forward the proposed solution and giving explanations of the underlying rationale.

Formulating design experience in terms of patterns is not an easy job especially in an unstructured field like 3DSSs; there is a long way to go before achieving a set of patternbased design resources that could be comparable, for size and quality, to the ones existing in other domains. We expect that, as in any other domain, also for 3DSSs the acceptability and adoption of patterns will have to answer the objections of skeptics: "How can I judge the quality of these patterns?" "Where is the empirical evidence of their benefits?" "At which degree this pattern language is "complete", i.e., covers through proper solutions the design space of this field?"

These are indeed general questions for any pattern language. Measuring "completeness" is a very complex issue that, to our knowledge, no studies have rigorously addressed. In most existing literature, the soundness of patterns is "proved" through the evidence that their problems and solutions occur in existing products or systems: the quality of the patterns presented in this paper, for example, is founded on the occurrence of their design problems and solutions in the 3DSS experiences developed in our projects, and in a number of other environments mentioned in the "known uses" section. The empirical study of frequency of use and measurable benefits of patterns for design is also very limited. The very few existing evaluations of pattern languages (e.g., in the HCI domain [22, 29]), focus on how patterns improve the design process; limited research explores the benefits of patterns in terms of quality of design results (with the notable exception of [89], which reports a study highlighting a significant correlation between the existence of patterns in commercial systems and the overall usability of those systems).

In summary, we foresee a long path ahead before we understand all possible problems and reliable solutions in 3DSS design, we reach maturity, and we achieve the degree of recognition and adoption that design patterns have in other fields. This paper is only an initial contribution that, we hope, will foster further works in this area. Many directions of research related to 3DSSs can be attractive for the WE community. These include not only the creation of pattern collections for 3DSS design, but also activities such as:

- Definition of quality assessment methods, needed to assess the "value" of 3DSS patterns. In particular, empirical studies on how design patterns affect the 3DSS design process and the quality of the resulting users' experience are important to support the evidence of patterns benefits or to confute it.

- Provision of pattern-based process models and design methodologies. 3DSS patterns are more likely to be adopted among practitioners and designers if they are systematically part of a structured design process. In software engineering, design 
patterns have been proven to be applicable in many stages of the design process: initial design, reuse, and re-factoring. Similar research attempts should be made in the 3DSS domain, by providing pattern-based process models specifically addressing the characteristics of to 3DSS design. Finally, patterns should become first order primitives in 3DD design models, as it happens in a number of WE methodologies [73]. These conceptual tools could help 3DSS designers to better to put patterns into the real design practice and to validate their impact on development projects.

Acknowledgements Our special thanks go to our colleagues and friends at HOC Lab who have been passionately working on the 3DDS projects discussed in many examples reported in our patterns. We are grateful to the members of the EC project TELL "Towards Effective network supported coLLaborative learning activities", and the attendants of EUROPLOP 2008 Authors' Workshop "E-Learning Design Patterns", for their precious feedbacks on the preliminary versions of some patterns reported in this paper. We thanks the anonymous reviewers for their constructive comments on our initial submission.

\section{References}

1. Active Worlds. http://www.activeworlds.com. Accessed 17 December 2008

2. Alben, L.: Quality of experience. Interactions 13(5), 12-15. ACM Press (1996)

3. Alexander, C.: The Timeless Way of Building. Oxford University Press, New York (1979)

4. Armstrong, M. A Handbook of Human Resource Management Practice (10th ed.). London: Kogan Page. (2006)

5. Arvola, M.: Interaction design patterns for computers in sociable use. International Journal of Computer Applications in Technology 25(2/3), 28-139 (2006)

6. Austin, H.: Design for what? Six dimensions of activity. Interactions, Sept+Oct. 2000, 17-22. ACM Press (2000),

7. Barab, S., Arici, A., Jackson, C.: Eat Your Vegetables and Do Your Homework: A Design-Based Investigation of Enjoyment and Meaning in Learning. Educational Technology 45(1), 15-20 (2005)

8. Barab, S., Thomas, M., Dodge, T., Carteaux, R., Tuzun, H.: Making learning fun: Quest Atlantis, a game without guns. Educational Technology Research and Development 53(1), 86-107 (2005)

9. Barbieri, T., and Paolini, P.: Cooperative Visits to WWW museum sites a year later: evaluating the effect. Proc. Museums\&Web2000, Minneapolis (2000)

10. Barbieri, T.: Networked virtual environments for the Web: the WebTalk-I and WebTalk-II Architectures. IEEE Computer Multimedia \& Expo 2000 (ICME), IEEE Press, New York (2000)

11. Batelle, J., O'Reilly, T.: Web 2.0 Opening Welcome. The State of the Internet Industry. Proc. Web 2.0 Conference, San Francisco, 5 October 2004

12. Benford, S., Greenhalgh, C., Rodden, T., Pycock, J.: To what extent is cyberspace really a space? Collaborative Virtual Environments. Communications of the ACM 44(7), 79-85 (2001)

13. Bickmore, T., Consolvo, S., Intille, S.: Engagement by design. In CHI 2009 Extended Abstracts, Boston (2009)

14. Borchers, J.O.: A Pattern Approach to Interaction Design. John Wiley \& Sons (2001)

15. Bouras, C., Philopoulos, A., Tsiatsos, T.: e-Learning through distributed virtual environments. Journal of Network and Computer Applications 24, 175-199 (2001)

16. Bradner, E., Mark, G.: Social presence with video and application sharing. Proc. GROUP'01, pp. 154163. Boulder (2001)

17. Brown, B., Bell, M.: CSCW at play: 'There' as a collaborative virtual environment. Proc. CSCW'04, Chicago (2004)

18. Brown, B., Bell, M.: Social interaction in 'There'. Proc. CHI 2004, pp.1465-1468. ACM,Vienna (2004)

19. Büscher, M., O'Brien, J., Rodden, T., and Trevor, J.: 'He's behind you': The experience of presence in shared virtual environments.In E.Churchill, D. Snowdon, A. Munro (eds.) Collaborative Virtual Environments, pp. 77-98. Springer-Verlag, Guilford (2001)

20. Buschmann, F., Meunier, R., Rohnert, H., Sommerlad, P., Stal, M.: Pattern-Oriented Software Architecture: A system of Patterns. Addison Wesley (1996)

21. Ceri S., Florian D. Facca F.M., Matera M. Model-driven Engineering of Active Context-awareness. World Wide Web, Volume 10, Number 4, December 2007, 387-413 
22. Chung, E.S., Hong, J.I., Lin, J., Prabaker, M.K., Landay, J.A., Liu, A.L.: Development and evaluation of emerging design patterns for ubiquitous computing. Proceedings of the Designing Interactive Systems Conference, pp. 233-242. Cambridge (2004)

23. Coplien, J.O., Schmidt, D.C.: Pattern Languages of Program Design. Addison-Wesley, (1995)

24. Counts, S., Fellheimer, E.: Supporting social presence through lightweight photo sharing on and off the desktop. Proc. CHI 04. Vienna (2004)

25. Counts S., Geraci, J. Incorporating Physical Co-presence at Events into Digital Social Networking. CHI 2005, April 2-7, 2005, Portland, Oregon, USA, 1308-1311

26. Csíkszentmihályi, M.: Flow: The Psychology of Optimal Experience. Harper and Row, New York (1990)

27. Damer, B.: Meeting in the ether. Interactions 14(5), 16-18 (2007)

28. Dearden, A.: Pattern Languages in HCI: a critical review. In Human Computer Interaction 21(1) (2006)

29. Dearden, A., Finlay, J., Allgar, L., McManus, B.: Evaluating pattern languages in participatory design. CHI '02 Extended Abstracts on Human Factors in Computing Systems, pp. 664-665. Minneapolis (2002)

30. Di Blas, N., Poggi, C.: 3D for Cultural heritage and education: evaluating the impact. In D. Bearman and J Trant (eds.) Selected papers from museums and the Web'06. Archives and museum informatics (2006)

31. Di Blas, N., Paolini, P., Poggi, C. Educational benefits: testing and evaluation of a collaborative $3 \mathrm{~d}$ world. In Proc. ED-MEDIA 2005, pp. 1002-1011. AACE (2005)

32. Di Blas, N., Paolini, P., Poggi, C., Torrebruno, A.: 3D Worlds for learning and play: 6 years of experience. In Proc. E-Learn 2008, AACE (2008)

33. Dix, A.J.: Computer-supported cooperative work-a framework. In D. Rosenburg and C. Hutchison (eds.) Design Issues in CSCW, pp. 23-37. Springer Verlag (1994)

34. Ducheneaut, N., Yee, N., Nickel, E., Moore, R.: “Alone Together"-Exploring the social dynamics of massively multiplayer online games. In Proc. CHI2006, pp. 407-416. ACM Press, New York. (2006)

35. Durlach, N., Slater, M.: Presence in shared virtual environments and virtual togetherness. PresenceTeleoperators and Virtual Environments 9(2), 214-217 (2000)

36. Erickson, T.: Interaction Design Patterns web site. http://www.pliant.org/personal/Tom_Erickson/ InteractionPatterns.html. Accessed 17 December 2008

37. Forlizzi, J., Battarbee, K. Understanding experience in interactive systems. In Proc. DIS2004, pp. 26168. ACM Press, Cambridge (2004)

38. Gamma, E., Helm, R., Johnson, R., Vlissides, J.: Design Patterns: Elements of Reusable Object-Oriented Software. Addison-Wesley (1994)

39. Garzotto, F., Forfori, M.: FaTe2: Storytelling edutainment experiences in 2D and 3D collaborative spaces. Proc. Interaction Design and Children 2006 (IDC'06), pp. 87-90, ACM Press (2006)

40. Garzotto, F., Forfori, M.: Hyperstories and social interaction in 2D and 3D edutainment spaces for children. In Proc. ACM Hypertext '06, pp. 46-55. ACM Press (2006)

41. Garzotto, F., Poggi, C.: Design patterns for collaborative learning in shared virtual worlds. In P. Goodyear and S. Retalis (eds.) Technology-enhanced learning: design patterns and pattern languages. IGI Global (2009- to appear)

42. Garzotto, F., Retalis, S.: Symposium on design patterns for e-learning. Proceedings of EDMEDIA 2004, Lugano, Switzerland (2004)

43. Garzotto, F., Paolini, P., Bolchini, D. Valenti, S.: Modeling-by-Patterns of Web Applications. Proceedings of the International Workshop on the World Wide Web and Conceptual Modeling, WWW CM'99, Paris (1999).

44. Goodyear, P., Avgeriou, P., Baggetun, R., Bartoluzzi, S., Retalis, S., Ronteltap, F., et al.: Towards a pattern language for networked learning. In: Banks, S., Goodyear, P., Hodgson, V., Jones, C., Lally, V., McConnell, D., Steeples, C. (eds.) Networked learning 2004, pp. 449-455. Lancaster University, Lancaster (2004)

45. Hall, E.T.: The Hidden Dimension. Doubleday, Garden City (1966)

46. Heeter, C.: Being There: The Subjective Experience of Presence. Presence: Teleoperators and Virtual Environments. MIT Press, Cambridge (1992)

47. http://cosy.ted.unipi.gr/tell

48. Hypermedia Design Patterns Repository http://www.designpattern.lu.unisi.ch/PatternsRepository.htm. Accessed 17 December 2008

49. Jäkälä, M., Pekkola, S.: From Technology Engineering to Social Engineering: 15 Years of Research on Virtual Worlds. The DATA BASE for Advances in Information Systems 38(4), 11-16 (2007)

50. Kraut, R., Egidio, C., Galegher, J.: Patterns of Contact and Communication in Scientific Research Collaboration. Intellectual Teamwork: Social and Technological Foundations of Cooperative Work, 149181. Lawrence Erlbaum Associates Publishers (1990)

51. Kumar R., Novak J., Raghavan P., Tomkins A. On the bursty evolution of blogspace. World Wide Web, 8, 2, June 2005, 159-178, Springer (2005) 
52. Lee, K.J.: What goes around comes around: an analysis of del.icio.us as social space. Proc. CSCW'06, November 4-8, 2006, Banff, Alberta, Canada PP 191-125

53. Lee, K.M., Nass, C.: Designing social presence of social actors in human computer interaction. Proc. CHI 03, pp. 289-296. ACM Press (2003)

54. Mahemoff, M.: Ajax design patterns. O’Reilly Media Inc., Sebastopol (2006)

55. Malone T. W.: Heuristics for designing enjoyable user interfaces: lessons from computer games. Proceedings of the 1982 conference on human factors in computing systems, Gaithersburg, Maryland (US), 63-68, ACM Press (1982)

56. Manolescu, D., Yoder, J.: Web 2.0 Pattern mining workshop. Workshop held at Tools 2008, Zurich (2008)

57. Marcus, A.: The challenge of user experience design. Interactions, Nov+Dec 2002, 29-35 (2002)

58. Martin, D., Rodden, T., Sommerville, I., Rouncefield, M., Hughes, J. A.: PoInter: patterns of interaction: a pattern language for CSCW (2002). http:/www.comp.lancs.ac.uk/computing/research/cseg/projects/ pointer/pointer.html. Accessed 17 December 2008

59. McCall, R., O’Neil, S., Carroll, F.: Measuring Presence in Virtual Environments. Proc. CHI 2004, pp.783-784. ACM, Vienna (2004)

60. McClellan, I.: User Experience' Design - a new form of design practice takes shape. In Proc. CHI'05, pp. 1097-1097. ACM Press (2005)

61. McEwan, G., Greenberg, S.: Community Bar Places for Collaboration. In L. Ciolfi, G. Fitzpatrick, L. Bannon (Eds) Workshop Proceedings Settings for Collaboration: The Role of Place, held in conjunction with ECSCW'2005. Paris (2005)

62. Mendes E., Mosley N. (Eds.),Web Engineering:Theory and Practice of Metrics and Measurement for Web Development, 2006, Springer-Verlag

63. Monk, A., Hassenzahl, M., Blythe, M., Reed, D.: Funology: designing enjoyment. In Proc. CHI'02, pp. 2135-145. ACM Press (2002)

64. Nardi, B., and Harris, J.: Strangers and friends: Collaborative play in World of Warcraft. In Proceedings of Computer-Supported Cooperative Work 2006. ACM Press, New York (2006)

65. Nickull, D., Hinchcliffe, D., Governor, J.: Web 2.0 Design patterns: What entrepreneurs \& information architects need to know. O'Reilly (2009-to appear)

66. Norman, D.A.: Emotional Design: Why we love (or hate) everyday things. Basic Books, New York (2004)

67. O'Reilly, T.: What Is Web 2.0-Design patterns and business models for the next generation of software. http:/www.oreillynet.com/pub/a/oreilly/tim/news/2005/09/30/what-is-web-20.html?page=5. Accessed 17 December 2008

68. Oded Nov, Mor Naaman, Chen Ye.: What drives content tagging: the case of photos on Flickr, CHI 2008, April 5-10, 2008, Florence, Italy, pp. 1097-2008

69. Paolini, P., Di Blas, N.: Multi-user virtual environments for education: a European experience. Proc. ELearn 06 Conference, pp. 1383-1394. AACE, Honolulu (2006)

70. Poggi, C., Torrebruno, A.: From the dead sea scrolls to social sports, passing through European history: an effective pedagogical format based on 3D worlds. Proc. of ED-Media 07, pp. 4240-4248. AACE, Chesapeake (2007)

71. Poggi, C., Di Blas, N.: Visual Communication in Virtual 3D Environments. In J. Grundy and J. Howse (Eds.), Proceedings of VL/HCC06. IEEE Symposium on Visual Languages and Human-Centric Computing, pp. 207-211. Brighton (2006)

72. Rossi, G., Schwabe, D., Garrido, A.: Design Reuse in Hypermedia Application Development. In Proc. of ACM Hypertext'97, Southampton (1997)

73. Rossi G.,Pastor O, Schwabe, Olsina L.(Eds.), Web Engineering: Modelling and Implementing Web Applications, Human-Computer Interaction Series , Vol. 12, 2007, Springer-Verlag

74. Sadowski, W., Stanney, K.: Presence in virtual environments. In: Stanney, K.M. (ed.) Handbook of Virtual Environments: Design, Implementation, and Applications, pp. 791-806. Lawrence Erlbaum Associates, Mahwah (2002)

75. Schaummer, T., Fernandez, A.: Patterns for virtual places. Proc. Europlop (2005)

76. Schümmer, T.: A Pattern Approach for End-User Centered Groupware Development. Verlag, Köln (2005)

77. Schummer, T., Lukosch, S.: Patterns for Computer-Mediated Interaction. Wiley (2007)

78. Schümmer, T.: GAMA - a pattern language for computer supported dynamic collaboration, Proc. EuroPLoP'04. Konstanz (2004)

79. Second Life Statistics (June 2007): http://static.secondlife.com/economy/stats 200707.xls. Cited in: Le Blanc, A., Bunt, J., Kwok,Y., Petch, J.: The Virtual Learning Space-An Interactive 3D Environment. Proc. Web3D '05: tenth international conference on 3D Web technology. (2005) 
80. Sheridan, T.: Musings on telepresence and virtual presence. Telepresence. Presence: Teleoperators and Virtual Environments 1(1), 120-126 (1992)

81. Slater, M., Steed, A.: A virtual presence counter. Presence 9(5), 413-434 (2000)

82. Sweetser, P., Wyeth, P.: Game Flow: a model for evaluating player enjoyment in games. ACM Computer and Entertainment 3(3), 1-23 (2005)

83. Tidwell, J.: thirty user interface patterns. http://designinginterfaces.com/. Accessed 17 December 2008

84. van Duyne, D.K., Landay, J.A., Hong, J.I.: The Design of Sites: Patterns, principles, and processes for crafting a customer-centered web experience. Addison-Wesley, Boston (2003)

85. van Welie, M.: Design patterns for Web, GUI, and mobile interfaces. http://www.welie.com. Accessed 17 December 2008

86. van Welie, M., van der Veer, G.C.: Pattern Languages in Interaction Design: Structure and Organization. In Rauterberg, M., Menozzi, M., Wesson, J. (eds) Proceedings of Interact '03, pp. 527-534, IOS Press, Amsterdam (2003)

87. Vorderer, P., Hartmann, T., Klimmt, C.: Explaining the enjoyment of playing video games: The role of competition. Proc. of the $2^{\text {nd }}$ International Conference on Computer Games. Pittsburgh 2003, ACM Press (2003)

88. Vygotsky, L.S.: Mind and Society: The development of higher psychological Process. Harvard University Press, Cambridge (1978)

89. Wania, C. E.: Examining the impact of an information retrieval pattern language on the design of information retrieval interfaces. PhD dissertation (2008) http://idea.library.drexel.edu/handle/1860/2829. Accessed 17 December 2008

90. Website of the Web Engineering community: www.webengineering.org. Accessed 17 December 2008

91. Whittaker, S., Frolich, D., and Daly-Jones, O.: Informal workplace communication: What is it like and how might we support it? Proc. Computer-Supported Cooperative Work 1994, pp. 131-138, ACM Press (1994)

92. Wilcox, L.M., Allison, R.S., Elfassy, S., Grelik, C.: Personal space in virtual reality. Transactions on Applied Perception (TAP) 3(4) (2006)

93. Young, K.S.: Internet Addiction: A New Clinical Phenomenon and Its Consequences. American Behavioral Scientist 48(4), 402-415 (2004)

94. Zhang, X., Furnas, G.W. Social interactions in multiscale CVEs. In Proceedings of the ACM Conference on Collaborative Virtual Environments, pp. 31-38. Bonn (2002)

95. Zimmerli, L., Verschure, P.F.M.J.: Delivering Environmental Presence through Procedural Virtual Environments. Proc. Presence'07, pp.335-338 (2007) 